\title{
Perspectiva de la teoría del valor de la fuerza de trabajo acerca del mercado laboral de El Salvador
}

Hazell Del Cid, Esmeralda Iraheta

Departamento de Economía Universidad Centroamericana José Simeón Cañas

Tercer lugar en el concurso de tesis del Departamento de Economía de la UCA, en las Jornadas "Francisco Javier Ibisate", 2014

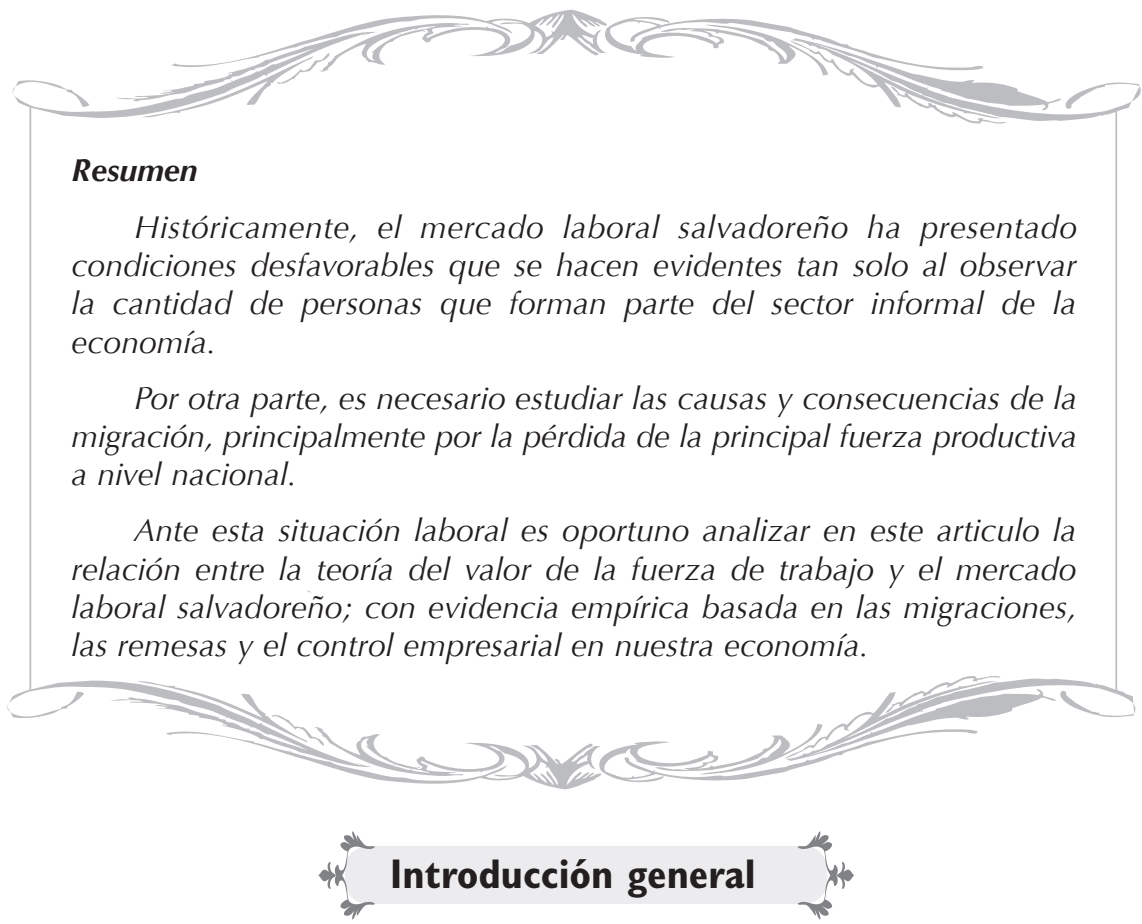

Este artículo tratará de analizar, desde la teoría del valor de la fuerza de trabajo, la relación estrecha que tienen el mercado laboral salvadoreño, la migración y el flujo de remesas que recibe el país. Como eje del trabajo, se empezará realizando un bosquejo sobre la base de la teoría del valor de la fuerza de trabajo de Carlos Marx desarrollada 
por Mario Montesino. En este esquema, se desarrollan conceptos tan diversos como la cobertura del valor de la fuerza de trabajo y su estrecha relación con la productividad y la eficiencia; así como de la plusvalía y las decisiones que toman los capitalistas para aumentarla.

En el contexto de la teoría del valor de la fuerza de trabajo, se analizará la migración en El Salvador (tanto la migración interna como la externa), así como sus causas, su historia y su impacto.

Se prestará una especial atención a una de las consecuencias principales y con mayor importancia de la migración: las remesas; realizando una pequeña síntesis de este particular fenómeno. Se analizará el impacto macroeconómico de las remesas en El Salvador y el papel importante que juegan debido a que generan un soporte económico beneficiando directamente a una enorme porción de la población.
Para finalizar se abordará el análisis de la migración, realizado bajo el contexto de la teoría del valor de la fuerza de trabajo que enfatizara la racionalidad de la reproducción de los trabajadores y el control empresarial en nuestra economía. Además se desarroIlará el modelo económico de Harris-Todaro, desarrollado por los economistas John Harris y Michael Todaro, que trata acerca de la migración de los sectores rurales a los urbanos y de cómo muchas de las personas que emigran terminan trabajando en el sector informal. Se demuestra cómo este modelo puede aplicarse adecuadamente a la realidad de El Salvador; en donde existe un gran movimiento migratorio del sector rural al urbano (principalmente debido a las enormes diferencias de ingreso entre ambos sectores y a la baja participación sindical en el sector rural) y en donde el sector informal representa aproximadamente el $50 \%$ de la Población Ocupada.

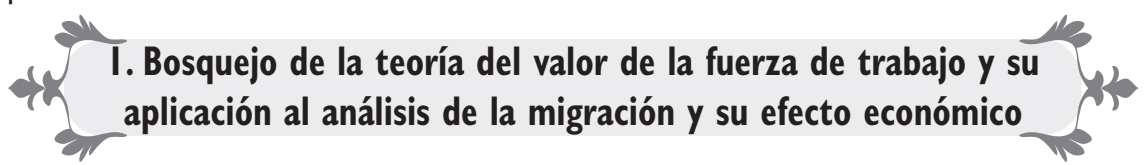

La economía cuenta con recursos escasos para su aprovechamiento y se encuentra inmersa en una realidad compleja de la cual no se puede desprender. Marx comprendió que la sociedad tiene como base un sistema de relaciones sociales de producción en interacción con la dinámica de las fuerzas productivas de la sociedad conformada por los medios de producción y la fuerza de trabajo. Tal dinámica puede ser entorpecida o favorecida por el comportamiento de las relaciones de producción. Según Marx, esta base constituye el fundamento material que sustenta y se halla inmerso en el ámbito de las 
relaciones jurídico políticas, y de las formas de la conciencia social, a lo que Ilamó superestructura jurídica política. Todo en conjunto representa el ámbito cambiante, en movimiento y desarrollo de la realidad social.

La propuesta de Montesino (2011) acerca de la teoría del valor de la fuerza de trabajo y la reproducción socioeconómica, fundamentada en Marx, puede expresarse en un modelo que parte de cuatro axiomas:

1- Existe una desarrollada división social del trabajo, lo que implica relaciones de intercambio.

2- Solamente el trabajo crea valor.

3- El trabajo tiene un doble carácter: concreto y abstracto.

4- La racionalidad reproductiva se expresa en bienes y/o mercancías necesarias.

En este enfoque, la dinámica de las fuerzas productivas se expresa en un conjunto vinculado de parámetros de reproducción:

1- Cobertura de la Fuerza de Trabajo.

2-Condiciones de partida del proceso de reproducción social que permita un desarrollo simultáneo de todos los sectores.
3- Condiciones de reproducción ampliada con intercambio balanceado.

4- Condiciones de reproducción ampliada con tasa de ahorro coherente con la tasa de inversión.

5- Condiciones de reproducción con desarrollo simultáneo y homogéneo en todos los sectores.

6- Condiciones de crecimiento y desarrollo dinámico.

7- Condiciones de reproducción monetaria estable.

8- Condiciones adecuadas de reproducción de la población.

9- Condiciones de reproducción ecológica.

Todos estos parámetros se encuentran relacionados e inmersos con los parámetros de la estructura social, los cuales son:

1- Ley de la plusvalía.

2- Ley de la ganancia.

3- Ley de la acumulación.

4- Ley de la formación de la ganancia media.

5- Principios monetarios en la economía capitalista. 
6- Principio del comportamiento tecnológico.

7- Ley de la población.

Este artículo, se enfoca en el parámetro de cobertura de la fuerza de trabajo y el efecto que las relaciones capitalistas de producción tienen en el aseguramiento adecuado de dicho parámetro; por lo tanto, primero se define el concepto de valor de la fuerza de trabajo: "Con esta denominación hay que entender el conjunto de las facultades físicas e intelectuales que existen en el cuerpo del hombre [mujer], en su personalidad viva y que debe poner en movimiento para producir cosas útiles" (Marx, C.; citado en Montesino, M).

En el capitalismo, la fuerza de trabajo es una mercancía y como tal debe tener valor, sin mencionar que la fuerza de trabajo es la única mercancía capaz de producir un valor mayor a la que esta posee, "como valor la fuerza de trabajo representa la cantidad de trabajo social realizado en ella" (Montesino, $M)$. La fuerza de trabajo debe de ser cubierta y se define su cobertura de acuerdo con las expresiones siguientes de Marx: "El tiempo de trabajo necesario para la producción de la fuerza de trabajo se resuelve pues, en el tiempo de trabajo necesario para la producción de esos medios de subsistencia; es decir, que la fuerza de trabajo tiene el valor exacto de los medios de subsistencia necesarios para quien la pone en funciones" (Ibid.: 177 citado en Montesino, M). Además, la fuerza de trabajo tiene un valor de uso, que consiste en su utilización; se utiliza para que pueda crear plusvalía de la cual se apropia el capitalista, por lo tanto, su uso se da mediante el trabajo. Si un trabajador no produce plusvalía, de nada le sirve al capitalista por lo cual se genera el desempleo, ya que "estas mercancías no poseen ningún valor de uso".

\subsection{Mercancía}

Como mercancía, la fuerza de trabajo se comporta de forma diferente a otras mercancías:

- El capitalista destruye las otras mercancías, al estar en sobreoferta con lo que se eleva su precio. La fuerza de trabajo desempleada no vale nada para el capitalista porque no le produce plusvalía y está sometida a un proceso de destrucción que se extiende a la fuerza de trabajo empleada debido a las bajas salariales que provoca la sobre-oferta.

- Las mercancías al aumentar su calidad siempre se venden a su mismo precio, ya que no se les ha aplicado más valor. La fuerza de trabajo al aumentar su calidad aumenta su productividad, con la misma fuerza de trabajo se produce más. 
- Si una mercancía se vende por debajo de su valor, mientras solo absorba el excedente esto no le genera ningún impacto en su recuperación al productor. Si la fuerza de trabajo se vende por debajo de su valor, esto se traduce en un impacto directo en sus condiciones, generando un deterioro en sus capacidades y reducción en su eficiencia.

En lo referente al valor de la fuerza de trabajo debe distinguirse entre valor concreto de la fuerza de trabajo (VCFT) que se encuentra medido en bienes y servicios que son necesarios para asegurar la reproducción o condiciones de existencia del trabajador y el valor abstracto de la fuerza de trabajo (VAFT) que se entiende como el tiempo o las horas socialmente necesarias de la jornada de trabajo que se requieren para reproducir (reponer) la fuerza de trabajo.

La remuneración de la fuerza de trabajo puede expresarse en dinero, igualmente la mayoría de satisfactores pueden también expresarse en dinero.

La cobertura del valor de la fuerza de trabajo se desprende de la remuneración la cual puede llegar a ser igual que el VCFT, pero por lo general es menor a este en el capitalismo.

\subsection{Productividad}

La relación entre la productividad con el VCFT y VAFT es:

1. Si la productividad aumenta y el VCFT se mantiene constante, el valor abstracto se reduce, la tasa de explotación aumenta y la tasa de los bienes para el capitalista aumenta.

2. Si la productividad aumenta y el VAFT se mantiene constante, el VCFT aumenta, la tasa de explotación permanece constante, el trabajador y el capitalista adquieren más bienes.

3. Si la productividad aumenta y el VCFT también, pero en una menor proporción que la productividad, entonces el VAFT disminuye y se eleva la tasa y masa de plusvalía.

4. Si la productividad se mantiene fija, las variaciones en el valor de la fuerza de trabajo se comportaran en sentido contrario a la masa y tasa de explotación.

\subsection{Cobertura de la FT y proceso productivo}

La producción depende de la magnitud de la fuerza de trabajo por ser la principal fuerza productiva de la sociedad, al ser la única capaz de generar valor y permitir su transferencia. 
A medida que a la fuerza de trabajo se le da menor cobertura, la productividad va disminuyendo, esto es debido a que al ser la fuerza de trabajo el principal componente para definir la productividad, cuando es pagada por debajo de su valor empieza a sufrir deficiencias. Esta descobertura implica que al bajar los salarios (remuneración), disminuye la capacidad reproductiva, esto disminuye la eficiencia y reduce la productividad, además, el nivel de producción se reduce por debajo del potencial. Esto no significa necesariamente que el trabajador este aceptando una reducción salarial; ya que si se trabaja con términos reales, lo que puede estar pasando es que se den procesos inflacionarios, el comportamiento dinámico puede ser la causa de esto o puede que en promedio esto es lo que esté sucediendo desde una perspectiva agregada.

Es importante mencionar que el valor de la fuerza de trabajo es una variable socioeconómica de difícil apreciación por parte de los empresarios capitalistas, esto es así debido a la conducta de ellos por reducirla al mínimo para poder incrementar la plusvalía.
Según Montesino, el valor de la fuerza de trabajo depende de:

1. Las necesidades de los bienes de manutención básicos.

2. Las necesidades sociales, morales y de carácter histórico.

Se puede hacer una relación con los procesos migratorios salvadoreños, comparando la economía de El Salvador con la de Estados Unidos. En economías con diferentes grados de cobertura como la de nuestro país, no se alcanza la producción óptima; mientras que en una economía con grado de cobertura total o casi total, la productividad mejorará y se obtendrá una producción óptima, el cual es el caso de Estados Unidos. Cuando la fuerza de trabajo emigra a un país con mayor cobertura, su nivel de vida mejora y las personas envían remesas a sus familiares a su país de origen, esta es la causa principal por la que los salvadoreños gastan en el país y experimentan un aumento en su bienestar, lo cual impulsa y mantiene a flote a la economía.

\section{Evidencia de la importancia del flujo de remesas en el desarrollo}

La economía salvadoreña se considera una economía muy particular con desarticulada capacidad productiva, crecimiento económico incipiente, con una balanza comercial deficitaria, endeudamiento excesivo y dolarización, sin embargo, a pesar de tener estas 
características la economía se ha mantenido a flote debido al gran flujo de remesas que recibe el país.

El surgimiento de esta economía de remesas está en la poca generación de empleo, las disparidades de desarrollo y salariales que existen entre nuestro país y el resto del mundo, por lo tanto no son unas simples transferencias si no que un pago al factor trabajo salvadoreño que se encuentra en el exterior.

\subsection{Impacto en la economía familiar}

En el país la distribución del ingreso muestra una marcada brecha entre el área urbana y el área rural, siendo esta última la que cuenta con la población de menores ingresos y precarias condiciones de vida. El ingreso promedio mensual de los hogares urbanos para 2012 fue de $\$ 594.47$ mientras que para los hogares rurales fue de \$338.55, lo cual respalda que las personas que viven en el área rural tienen más dificultades para satisfacer sus necesidades.

Si bien el ingreso promedio ha tendido el alza esto podría deberse en mayor medida porque hay una influencia de remesas y no por una mejoría en la distribución del ingreso en el país, según datos de la Revista Realidad 2004, las remesas aumentaron el ingreso familiar en la zona urbana en un $8.2 \%$ y $9.7 \%$ en la zona rural. Es clara la influencia de las remesas pues en periodo de post crisis estos ingresos promedio disminuyeron al igual que el nivel de remesas percibidas en esos años.

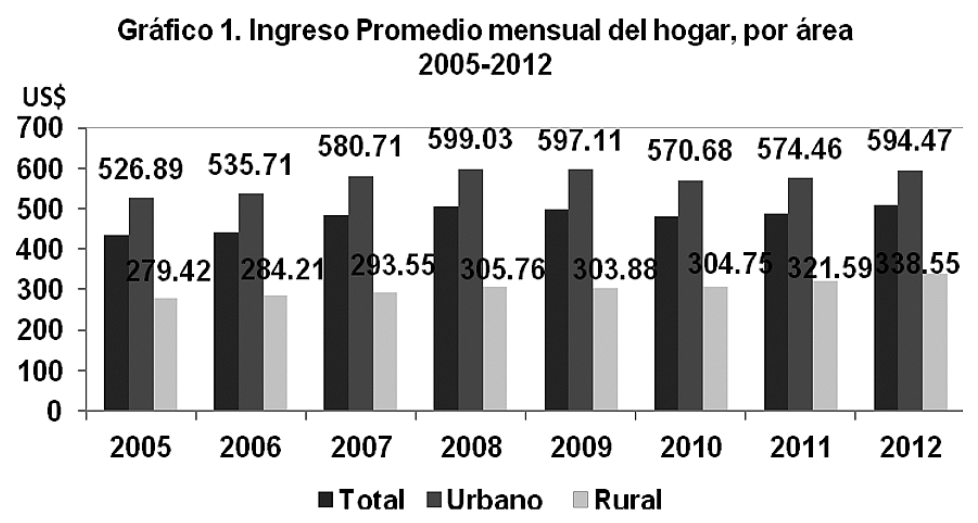

Fuente: Ministerio de Economía, Dirección General de Estadística y Censos, EHPM, 2012 
Teniendo en cuenta la situación anteriormente planteada de los ingresos, las remesas pasan a tener un papel muy importante en los hogares salvadoreños, convirtiéndose en ingresos constantes y necesarios para dichos hogares.

El índice de desarrollo humano de El Salvador, el cual de acuerdo al PNUD $^{1}$ en 1990 era de 0,528 y para el año 2012 era de 0,680, coincide con el periodo de auge de la emigración. Las remesas han contribuido a la reducción de la desigualdad de la distribución del ingreso, como se observa en el siguiente cuadro el coeficiente de Gini es mayor si se excluyen las remesas del ingreso familiar:

\section{Cuadro 1. Coeficiente de GINI}

\begin{tabular}{|c|c|c|c|c|}
\hline Año & $\begin{array}{c}\text { Relación entre quintil } \\
\text { más rico y más pobre } \\
\text { (ingreso familiar) }\end{array}$ & $\begin{array}{c}\text { Relación entre quintil más } \\
\text { rico y más pobre (ingreso } \\
\text { familiar excluye remesas) }\end{array}$ & $\begin{array}{c}\text { Coeficiente de GINI } \\
\text { (ingreso familiar) }\end{array}$ & $\begin{array}{c}\text { Coeficiente de GINI } \\
\text { (ingreso familiar } \\
\text { excluye remesas) }\end{array}$ \\
\hline 2000 & 18.8 & 26.7 & 0.516 & 0.543 \\
\hline 2004 & 14.5 & 23.8 & 0.478 & 0.515 \\
\hline 2009 & 12.5 & 17.9 & 0.473 & 0.505 \\
\hline
\end{tabular}

Fuente: Informe sobre Desarrollo Humano El Salvador 2010

En el país, un total de 1,238,294 personas reciben remesas, de las cuales, el $23.27 \%$ es del área rural. Esto es relevante, porque en esta área se encuentran 241,367 hogares $^{2}$ en pobreza relativa y extrema. Por otra parte, un $17.69 \%$ son las personas que perciben remesas en el área urbana, lo que es un porcentaje también significativo.

\section{Cuadro 2. Personas que perciben remesas por sector}

\begin{tabular}{|l|c|c|c|}
\multicolumn{1}{r|}{ Área } & Personas con remesa & Total personas & Porcentaje \% \\
\hline Rural & 546,483 & $2,338,850$ & $23.37 \%$ \\
\hline Urbana & 691,811 & $3,910,412$ & $17.69 \%$ \\
\hline Total País & $1,238,294$ & $6,249,262$ & $19.81 \%$ \\
\hline
\end{tabular}

Fuente: Ministerio de Economía, Dirección General de Estadísticas y Censos. EHPM, 2012

De acuerdo a la Encuesta de Hogares y Propósitos Múltiples (EHPM) del año 2012, los hogares receptores de remesas eran 322, 927 en todo el país, considerando el $74 \%$ de estos hogares como no pobres mientras el $26 \%$ restante están en una situación de pobreza, por lo cual el impacto de las remesas en la subsistencia de estas familias es evidente. 
Cuadro 3. Hogares receptores de remesas 2012

\begin{tabular}{|l|c|}
\hline \multicolumn{1}{|c|}{ CONDICIÓN DE POBREZA } & HOGARES \\
\hline POBREZA & 82,453 \\
\hline POBREZA EXTREMA & 15,312 \\
\hline POBREZA RELATIVA & 67,141 \\
\hline NO POBREZA & 240,474 \\
\hline TOTAL & 322,927 \\
\hline
\end{tabular}

Fuente: Ministerio de Economía, Dirección General de Estadísticas y Censos. EHPM, 2012

Además, es importante destacar el monto mensual que representan las remesas para los hogares que las reciben, porque el 39\% de estos hogares tienen un ingreso mensual mayor que el salario mínimo ${ }^{3}$ y por lo tanto el salario que impulsa a las personas que reciben remesas a trabajar se ha elevado.

Asimismo, las remesas mensuales recibidas superan el salario mínimo establecido en 2011 para el sector agropecuario, comercial, industrial y maquilero que son \$105, \$224.10, \$219.30 y $\$ 187.50$ respectivamente, por lo tanto es innegable que las remesas logran atenuar las disparidades en los ingresos que existen en el país, han contribuido a la disminución de la pobreza y hacen posible que algunos hogares estén por encima de la línea de pobreza.

Las remesas representan un ingreso constante en el presupuesto de los hogares y el gasto de dichas remesas para la mayoría de estas familias está destinado principalmente para el consumo de necesidades inmediatas y servicios básicos como la educación, vivienda y salud que se consideran como parte fundamental para la mejora en las capacidades productivas de la fuerza de trabajo, pues en el país no están al alcance de una gran parte de la población, lo que garantiza un mayor bienestar de las familias receptoras de remesas.

Además, es destacable que en esta estructura de gastos la parte que se puede considerar como uso "no productivo" de las remesas, porque incentiva la demanda de sectores no productivos como el sector de servicios es mínima, lo cual refuerza una generada controversia de la posibilidad de que las remesas se conviertan en un medio para generar inversión. Aunque hay que tener claro que los sectores de la economía poseedores de los medios de producción, adonde finalmente se destina el dinero percibido por las remesas, son los que deben de asegurar una correcta inversión, es decir que está en manos de los capitalistas la inversión hacia la que se destinen. 
Cuadro 4. Destino de la remesa

\begin{tabular}{|l|r|c|}
\hline \multicolumn{1}{|c|}{ DESTINO DE LA REMESA MENSUAL RECIBIDA } & TOTAL HOGARES & $\begin{array}{c}\text { ESTRUCTURA } \\
\text { PORCENTUAL }\end{array}$ \\
\hline CONSUMO & 301,081 & $85.52 \%$ \\
\hline VIVIENDA & 6,329 & $1.80 \%$ \\
\hline COMERCIO & 1,060 & $0.30 \%$ \\
\hline GASTOS MÉDICOS & 10,776 & $3.06 \%$ \\
\hline GASTOS EN EDUCACIÓN & 23,302 & $6.62 \%$ \\
\hline COMPRA INSUMOS AGRÍCOLAS & 863 & $0.25 \%$ \\
\hline AHORRO & 6,419 & $1.82 \%$ \\
\hline OTROS & 2,232 & $0.63 \%$ \\
\hline
\end{tabular}

Fuente: Ministerio de Economía, Dirección General de Estadísticas y Censos. EHPM, 2012

Con respecto al uso de las remesas como inversión, en los últimos años se ha dado el auge de las remesas colectivas, las cuales han beneficiado a comunidades que tienen una gran cantidad de población migrante y esto ha posibilitado que estas comunidades puedan invertir en infraestructura y servicios básicos.

\subsection{Impacto macroeconómico}

Para medir el impacto de la migración, las variables más utilizadas han sido el monto de las remesas, la comparación entre el Producto Interno Bruto (PIB) y las remesas respecto a las exportaciones e importaciones.

Primeramente en el caso de las remesas, el ingreso por ellas ha mantenido una tendencia creciente al pasar de los años.

Los salvadoreños que se han establecido en otros países, principalmente en EE.UU., o tienen familiares fuera del país, junto con la débil capacidad de la generación de empleos en el sector formal del país, han estimulado el flujo de más emigrantes y por lo tanto un incremento anual del ingreso por remesas.

Desde 2000 al 2012 el promedio de los envíos de dinero desde otros países ha crecido en promedio un $7.23 \%$ anual presentándose el mayor incremento del año 2003 al 2004 donde se obtuvo un crecimiento del $21.01 \%$ respecto al año anterior, además se observa un decrecimiento del 2008 al 2009 por un total de $\$ 354.9$ millones de los ingresos en concepto de remesas, esto debido a la crisis.

Finalmente para el año 2012 el monto de las remesas ha sido de $\$ 3910.9$ millones y es de esperar que en corto plazo este ingreso por remesas no disminuirá sobre todo porque las causas de la migración no han cambiado y porque cada año aumenta más el número de emigrantes. 
Grafico 2. Ingresos por remesas familiares de El Salvador, 2000-2012

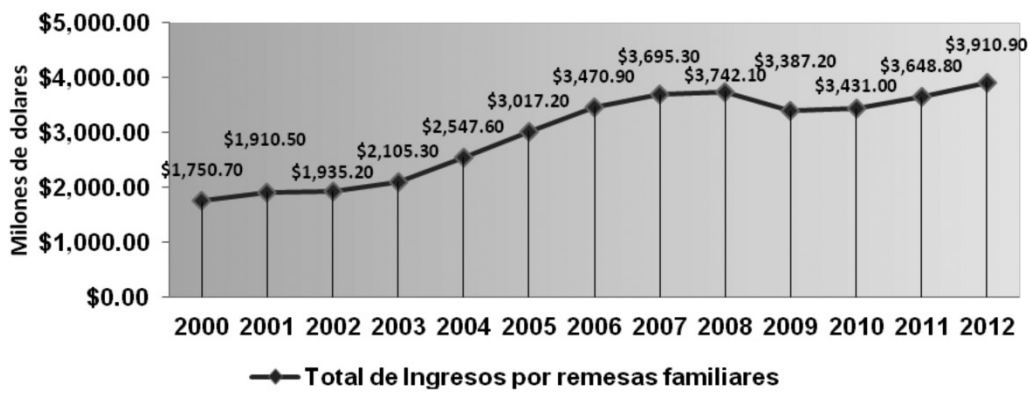

Fuente: Elaboración propia en base a Revista Trimestral Banco Central de Reserva (BCR) varios años.

En segundo lugar, al comparar el flujo de remesas versus PIB este tendió a caer especialmente del 2006 al 2011 pese a que el ingreso de remesas ha sido continuo al alza pero se veía disminuido respecto al crecimiento del PIB. El crecimiento de los montos por envíos de dinero al nivel de familias, ha estado en aumento, a pesar del persistente estancamiento económico ya que para el 2012 las remesas han llegado a representar el $16.4 \%$ del PIB. Está claro entonces que las remesas son producto de la explotación de la fuerza de trabajo y son necesarias e imprescindibles para las familias salvadoreñas.

\section{Grafico 3. Remesas como porcentaje del PIB 2000-2012}

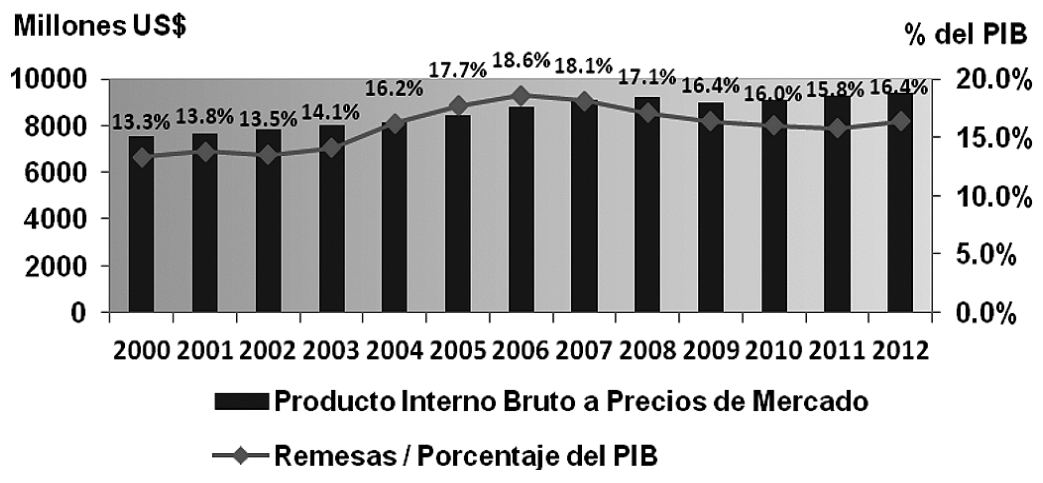

Fuente: Elaboración propia en base a Revista Trimestral Banco Central de Reserva (BCR) varios años.

El flujo de remesas permite la estabilidad macroeconómica de nuestro país, así como financiar una buena parte del déficit comercial y la balanza de pagos. La cantidad de ingreso que representan para el país es superior a la Inversión Extranjera Directa (IED) realizada, por ejemplo 
de acuerdo a la CEPAL ${ }^{4}$ en el 2012 la IED fue de $\$ 350$ millones por año, versus $\$ 3910.9$ millones que ingresaron al país por las remesas en el mismo período. Por otra parte, la relación de las remesas como porcentaje de exportaciones en los últimos años ha ido decreciendo, sin embargo tienen un valor considerablemente significativo y las remesas siguen siendo un importante ingreso para El Salvador. En el siguiente grafico se muestra que en el 2012 la remesas representaron el $92.39 \%$ de la exportaciones, excluyendo la maquila.

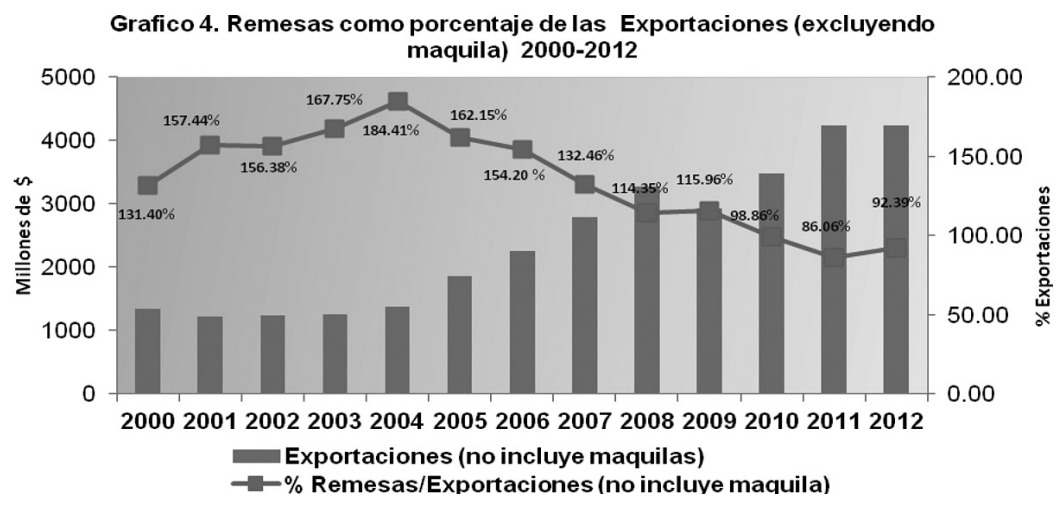

Fuente: Elaboración propia en base a Revista Trimestral Banco Central de Reserva (BCR) varios años.

Respecto a la relación de las remesas como porcentaje de las importaciones, también se observa que desde el año 2009 tiene una tendencia relativamente decreciente, aun así para el año 2012 las remesas representaban un $40.94 \%$ de las importaciones. Este tipo de comportamiento coincide con los patrones de consumo que se han perpetuado con las remesas y que también en gran parte ayudan a financiar el déficit comercial.

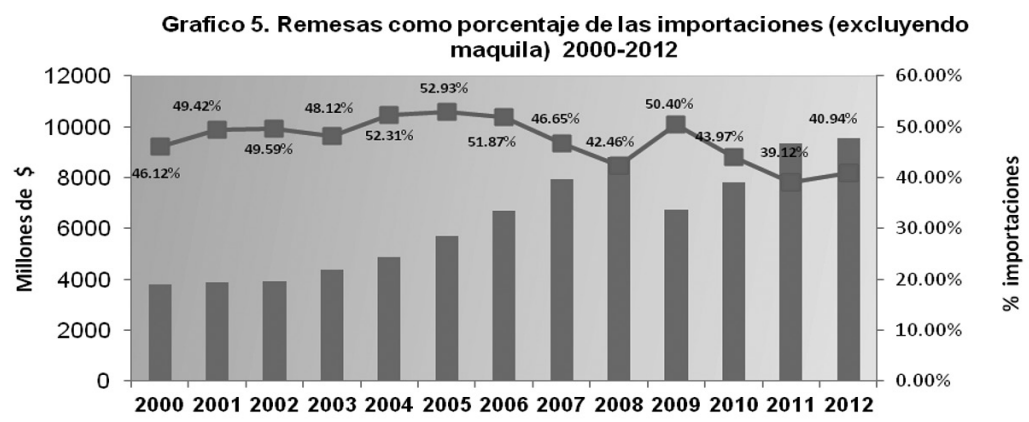

Importaciones (no incluye maquila)

$-\%$ Remesas/Importaciones (no incluye maquila)

Fuente: Elaboración propia en base a Revista Trimestral Banco Central de Reserva (BCR) varios años. 
Las remesas han contribuido en la inversión en capacidades productivas de la fuerza de trabajo, porque han mejorado las condiciones de vida de varios hogares salvadoreños $y$, por lo tanto, el gasto de esta remesas ha respondido a las necesidades de reproducción de la vida de las personas, lo cual es muy importante para el desarrollo.

\section{El proceso migratorio en El Salvador}

El proceso migratorio de $\mathrm{EI}$ Salvador ha estado marcado históricamente por diversos aspectos tanto económicos como sociales, aunque los aspectos económicos han sido predominantes en las últimas décadas. Mediante el recuadro siguiente podremos mostrar en cuantas etapas en El Salvador se han dado procesos de migración intensivos:

\section{Cuadro 5. Resumen del proceso migratorio en El Salvador}

\begin{tabular}{|c|l|}
\hline Primera etapa (1920-1960) & $\begin{array}{l}\text { La mayoría de migrantes salvadoreños salían del país impulsados principalmente } \\
\text { por la falta de acceso a la tierra y oportunidades de empleo, especialmente en las } \\
\text { áreas rurales la mayoría se dirigía hacia el norte de Honduras a las plantaciones } \\
\text { de banano, además se calcula que para los años treinta, aproximadamente } 25 \text { mil } \\
\text { salvadoreños habían emigrado (Winschuh 1997) }\end{array}$ \\
\hline Segunda etapa (1970-1979) & $\begin{array}{l}\text { La llamada Guerra de las Cien Horas, entre El Salvador y Honduras en julio de 1969, } \\
\text { tuvo un impacto profundo sobre los asentamientos salvadoreños que trabajaban en } \\
\text { tierras hondureñas, y estos fueron obligados a regresar a El Salvador, el rompimiento } \\
\text { del MERCOMUN agravo la situación socioeconómica del país, y los refugiados } \\
\text { demandaban trabajo, educación, salud y albergues. Los migrantes de este periodo } \\
\text { comienzan a dirigirse hacia los Estados Unidos en números sin precedentes. }\end{array}$ \\
\hline Tercera etapa (1980-1991) & $\begin{array}{l}\text { En esta época, correspondiente al conflicto armado entre insurgentes y el gobierno, } \\
\text { existía una inestabilidad social de inseguridad, durante este periodo el flujo migra- } \\
\text { torio se realizó por el camino de la legalización del estatus migratorio, con aquellas } \\
\text { personas que llegaron en los sesenta y setenta a los Estados Unidos. }\end{array}$ \\
\hline Cuarta etapa (1992-2005) & $\begin{array}{l}\text { Esta tiene como punto de partida los Acuerdos de Paz, que permitió el retorno de } \\
\text { emigrados (personas de altos recursos y Políticos), sin embargo una vez pasada la } \\
\text { burbuja de la paz, reaparecen viejos problemas como el empleo, la crisis de la } \\
\text { rentabilidad de la agricultura, problemas naturales y coyunturales y las crecientes } \\
\text { historia de progreso de las personas que migraron décadas anteriores, esto impulso } \\
\text { una masiva migración de la población hacia los Estados Unidos. }\end{array}$ \\
\hline
\end{tabular}

Fuente: Elaboración propia en base al Informe sobre desarrollo humano El Salvador, Capitulo 1 Dinámica de los migrantes internacionales salvadoreñas, 2005

Se puede ver que la migración salvadoreña ha estado marcada por factores repetitivos como el desempleo, la falta de una vida digna y los bajos ingresos, considerando dichos aspectos como eje fundamental para que la población tome la decisión de migrar. 


\subsection{La Teoría del Capital Humano}

La OCDE ${ }^{5}$ define el capital humano como los conocimientos, habilidades, competencias y atributos incorporados en los individuos y que facilitan la creación de bienestar personal, social y económico ${ }^{6}$. Estas habilidades son consecuencia de un proceso que se da en la formación de la persona a lo largo de su vida, en la cual esta tiene acceso a educación o también puede llevarse a cabo mediante la oportunidad de trabajos que le permiten desarrollar nuevas habilidades con las cuales el individuo pueda capacitarse tanto para ganarse la vida como para lograr un mayor crecimiento económico para el pais ${ }^{7}$.

Para contextualizar lo anterior en El Salvador, se muestran los años de educación promedio según los niveles de logros educacionales de la población de acuerdo con la duración de cada nivel:

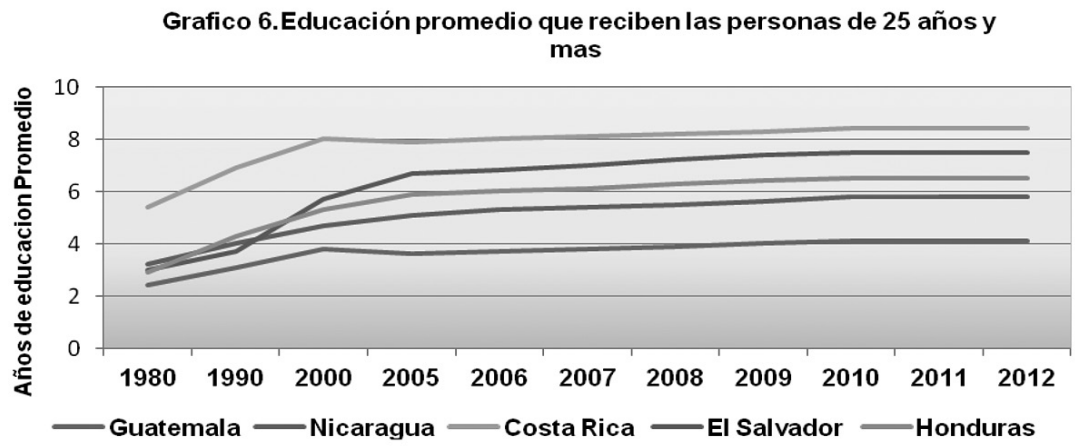

Fuente: HDRO updates of Barro and Lee (2011) estimates based on UNESCO Institute for Statistics data on education attainment (2012) and Barro and Lee (2010) methodology. Indicadores internacionales de desarrollo humano PNUD.

Es indiscutible que El Salvador ha tenido un aumento en el nivel de educación promedio desde 1980 hasta la fecha ya que de un promedio de tres años de educación pasó a tener un promedio de 7.5 años de educación ${ }^{8}$. Si se comparan estas cifras con nuestros países vecinos se puede ver que nuestro país se ubica en el segundo lugar por debajo de Costa Rica, lo cual evidencia que la población salvadoreña se ha visto beneficiada, pero además los salvadoreños buscan incrementar beneficios económicos del capital humano como mayores ingresos mediante más educación, pues la calidad de la fuerza de trabajo es sólo uno de los factores que determinan el crecimiento económico. Los países pueden tener niveles educativos similares en términos generales y sin embargo mostrar 
grandes variaciones en su ritmo de crecimiento.

Según el informe del censo decenal de 2000, aproximadamente el $63 \%$ de las mujeres y el $65 \%$ de los hombres de origen salvadoreño que vivían en Estados Unidos no habían completado la escuela secundaria ${ }^{9}$, esto refleja las condiciones de calificación de las personas que emigran. Cabe destacar que actualmente en $\mathrm{El}$ Salvador las personas tienen una educación promedio de 7.5.

El empleo es uno de los factores más importantes que determinan la reproducción de la fuerza de trabajo. La EHPM 2012 muestra que la PEA, que realiza alguna actividad económica u ofrece su fuerza de trabajo al mercado laboral, está constituida por 2, 724,754 personas. De éste total el $59.4 \%$ es representado por los hombres y el $40.6 \%$ por las mujeres. Al caracterizar la PEA por área geográfica, la EHPM reveló que el área urbana participa en $66.4 \%$ del total, mientras que la zona rural lo hace en un $33.6 \%$. De manera que el análisis se centrará en la población urbana, debido a que en este sector es donde se encuentra la mayoría de la PEA.

El subempleo durante el periodo 2005-2012 ha tenido una tendencia creciente, lo cual explica que la falta de cobertura de la fuerza de trabajo se está profundizando más a medida que pasa el tiempo, pudiendo ser este uno de los factores por los cuales las personas deciden emigrar y buscar nuevas posibilidades.

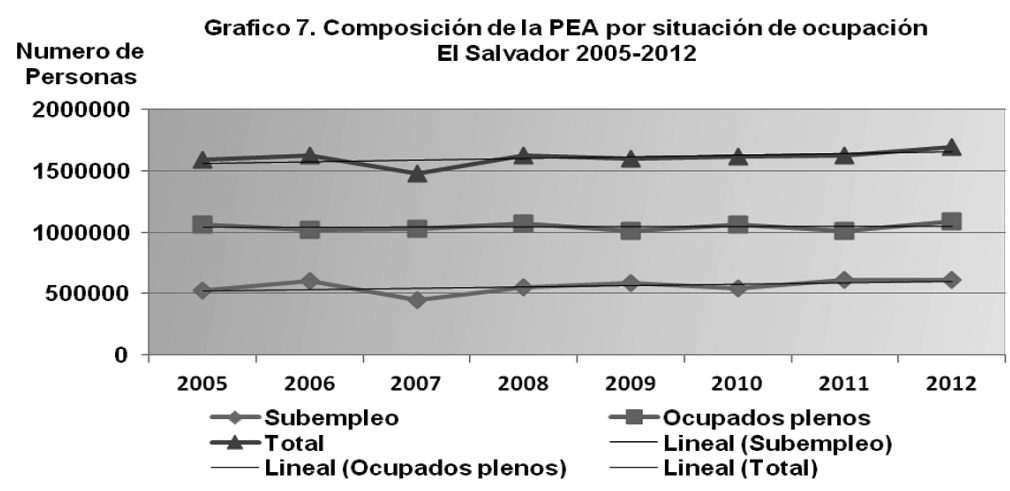

Fuente: Elaboración propia en base EHPM 2005-2012, Total País Urbano Ocupados por rama de actividad económica, Disponible en línea http://www.digestyc.gob.sv 
Si se analiza dentro de los ocupados plenos por sector, vemos que existe una probable migración de la fuerza laboral del sector manufacturero al sector servicios desde 1990 al 2010, lo cual es algo consecuente dado que no deben de ser altamente calificados para ejercer un servicio además que el salario es mayor, esto como consecuencia del alto nivel de demanda de servicios que surge a partir de los ingresos o remesas provenientes en su mayoría de Estados Unidos e incluyendo el resto del mundo.

Grafico 8. Ocupados por Actividad Económica

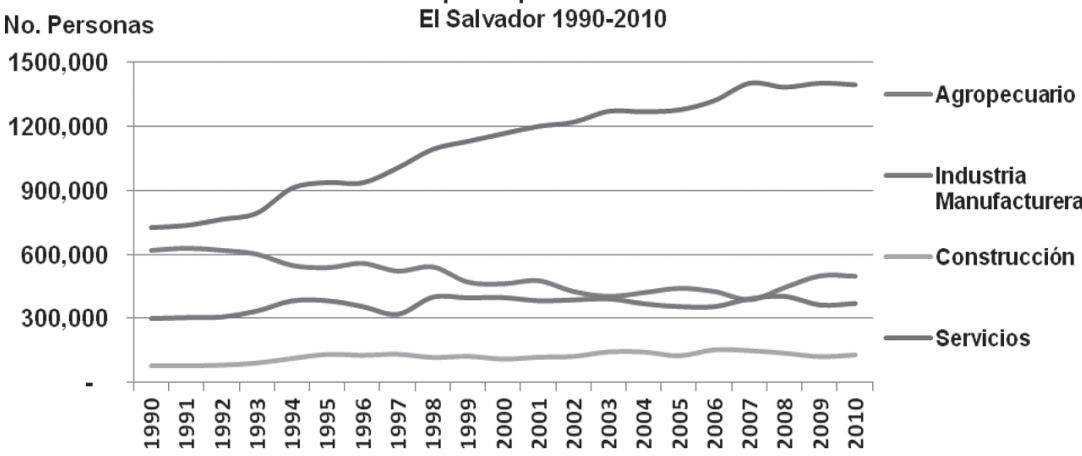

Fuente: Elaboración propia en base EHPM 1990-2010 Ocupados en número de personas, Biblioteca de la DIGESTYC

\subsection{El fenómeno de la migración}

Se observa en el siguiente gráfico, que El Salvador ha tenido una participación muy marcada en la migración. En este periodo (1930-2011) se legalizaron 753,220 personas, marcando a nivel centroamericano un número de personas muy importante, mientras que si se compara con Costa Rica en este periodo fueron un total de 105,147 las cuales emigraron legalmente. Esto podría deberse a que Costa Rica se encuentra con mejores niveles de crecimiento económico y mejor educación promedio, tanto es así que para el año 2009 la tasa de desempleo visible para este país era de 4.9 y el invisible de $2.9^{10}$. Al comparar contra El Salvador 6.8 y 8.0 respectivamente, esto nos refleja la falta de cobertura del valor de la fuerza de trabajo en el sector urbano, de manera que evidencia el por qué los salvadoreños emigran en una mayor proporción que la de Costa Rica. Si se evalúa para el año 2011 en el caso de El Salvador, 18,477 personas emigraron de manera legal, por tanto continua siendo mayor el número de personas en relación con Costa Rica que para el mismo año solo fue de 2,230 personas. 


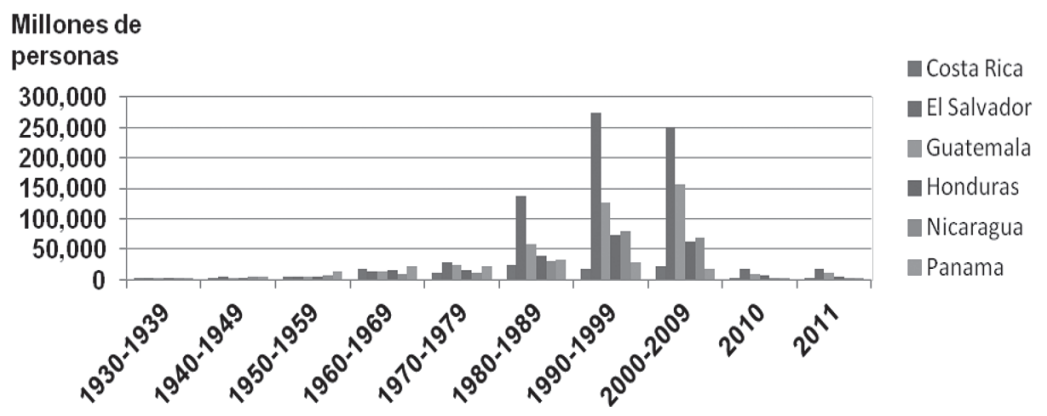

Fuente: Elaboración propia en base 2011 Yearbook of Immigration Statistics.

La migración consiste en el desplazamiento de las personas de su país de origen hacia un país de destino. Con esta decisión que toman los migrantes van implícitas una serie de razones, entre las que se pueden mencionar la pobreza, la inseguridad y la falta de acceso a oportunidades en el país de origen de las personas. Si bien es cierto, que las condiciones en las que se encuentran viviendo estas personas no son dignas, en el proceso de migración ilegal se enfrentan a una serie de dificultades como secuestros, violaciones, discriminación e incluso la muerte.

A continuación se muestra una tendencia muy importante con los trabajadores salvadoreños ilegales especialmente en Estados Unidos. La característica más relevante de ese proceso de inserción es la elevación de su nivel de ingresos. Si se toman como validas las cifras del Instituto Mumford, de 1 millón 117 mil 959 salvadoreños viviendo en Estados
Unidos en 2000, se considera que, entre ese grupo poblacional, quienes trabajaban generaban un ingreso promedio por persona anual de US\$23 mil 584, que si se ve de manera general, el ingreso total generado por los salvadoreños residentes en Estados Unidos a la altura de ese año fue de US\$13 mil 969 millones el cual habría sido equivalente al 106\% del PIB de El Salvador reportado por el BCR para el mismo año (US\$13 mil 134 millones). ${ }^{11}$

En nuestros días la cantidad de salvadoreños en el exterior no se logra definir con exactitud. Pero según datos del "Informe alternativo relativo al cumplimiento por $\mathrm{El}$ Salvador de la Convención Internacional sobre la Protección de los Derechos de todos los Trabajadores Migratorios y sus familias":

- Entre 500 y 600 personas salvadoreñas emigran diariamente, principalmente hacia los Estados Unidos 


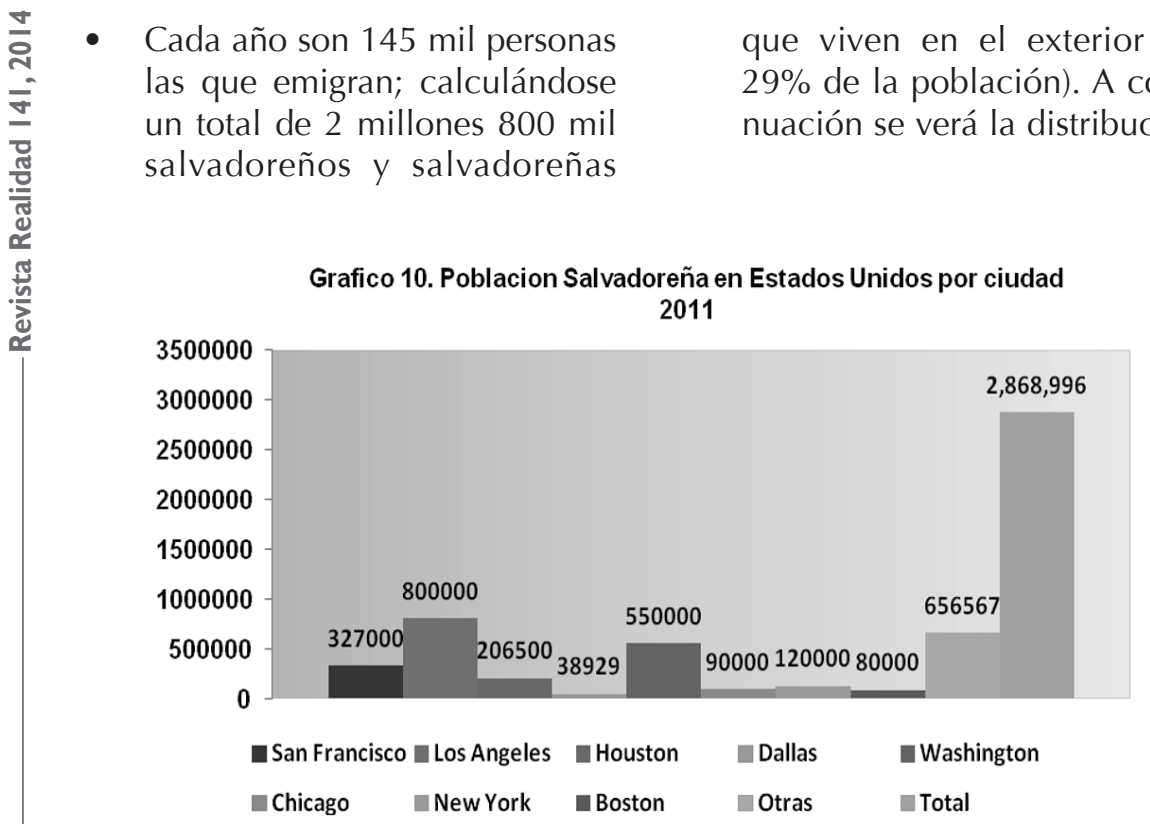

Fuente: Elaboración propia a partir de datos del PNUD 2011.

- Al menos un $88 \%$ se ha concentrado en los Estados Unidos (2.7 millones de salvadoreños)

Anteriormente se mencionó que en su mayoría las personas emigran por las condiciones de pobreza en las que se encuentran, pero no hay que pasar por alto que además está ocurriendo un proceso migratorio de profesionales que constituye una tasa del $31 \%$ de la emigración cualificada, conocido como fuga de cerebros, que se refiere a la transferencia de recursos en la forma de capital humano y aplica a la migración de mano de obra cualificada de los países en desarrollo a los países desarrollados.
Estos flujos representan un $30 \%$ del total emigrante a países de OCDE ${ }^{12}$. Esto refleja que en el país se está perdiendo mano de obra cuya calificación podría ser valiosa si hubiese capacidad para absorberla y esta se aplicase, mas sin embargo se ven en la necesidad de migrar puesto que no logran ser absorbidos dentro del sector formal.

Una de las expresiones más conocidas de las prácticas de los migrantes salvadoreños es el envío de remesas, cuyo impacto macroeconómico es de tal magnitud, que en 2008 representaban el $18 \%$ del PIB. ${ }^{13}$ Es de recalcar la importancia que han ido mostrando las remesas en nuestro 
país, si bien han contribuido a la disminución de la desigualdad en lo que a ingresos se refiere, también es importante analizar que la situación del empleo no ha mejorado en El Salvador, pues más del $50 \%$ de la población que labora sigue situándose en el sector informal de la economía. Según datos recientes del Banco Central de Reserva ${ }^{14}$ las remesas familiares enviadas por salvadoreños residentes en el exterior en el mes de Septiembre de 2013, ascendieron a US\$315.4 millones, aumentando en US\$12.7 millones y registrando una tasa de crecimiento del $4.2 \%$ en relación al mismo mes del año anterior. Durante el período eneroseptiembre de 2013, ingresaron al país un total de US\$2,931.7 millones, cifra que creció en $1.3 \%$, equivalentes a US\$38.4 millones más que lo registrado en el mismo período del año anterior. Mientras el Ingreso Nacional Bruto Disponible ha ido aumentando el Producto Interno Bruto lo ha hecho en una menor proporción pues el efecto de las remesas que son contabilizadas como transferencias corrientes generan esta situación que se observa a continuación:

\section{Grafico 11. PIB, Ingreso nacional bruto e Ingreso Nacional Bruto Disponible, (en dolares 1990)}

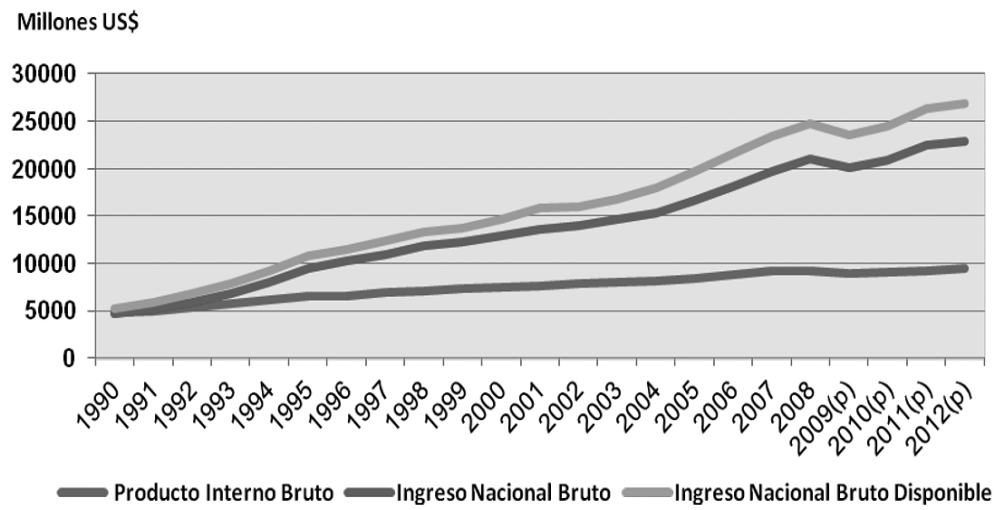

Fuente: Elaboración propia en datos de BCR 1990-2012 ver página web: www.bcr.gov.sv

Esto demuestra el impacto de las remesas en la economía salvadoreña como resultado de la enorme fuga de mano de obra, que se da a raíz de la insuficiente cobertura del valor de la fuerza de trabajo, debido a los salarios de miseria que afectan directamente la eficiencia del trabajador y por lo tanto, la productividad. Este es un aspecto que tiene que ver mucho con el desarrollo ya que muchos 
países son subdesarrollados, debido al desperdicio de la principal fuerza productiva del país; muchas veces es preferible la utilización de maquinas en el proceso productivo, a costa de la mano de obra, es decir, se está desperdiciando un gran recurso que puede llevar a una economía al crecimiento y al desarrollo, pero siempre y cuando se garanticen las condiciones de existencia del trabajador así como la reposición del desgaste que se da en el proceso productivo.

\subsubsection{El modelo del proceso migratorio y el desarrollo económico.}

Este modelo desarrollado por Montesino (2011) parte de que el proceso migratorio se da por 3 etapas:

- Formación del torrente de migrantes en el lugar de partida

- Desplazamientos propiamente dichos

- Adaptación al nuevo lugar de residencia

Además, la conciencia del individuo se ve afectada por dos factores: la posibilidad real de migrar y el estímulo de migrar.

La primera hace referencia a que el individuo tomará en cuenta su situación previa y su condición presente, sobre todo, en lo referente a la reproducción de su fuerza de trabajo y de su familia; además, también hará planes respecto a donde llegará cuando vaya a migrar, las posibilidad de empleo, su alimentación y seguridad, con el fin de ver si le conviene salir del país o no.

El estímulo de migrar se refiere a que el individuo necesita información acerca de los gastos en que incurre al migrar y las ventajas que puede tener al hacerlo. Además, toma en cuenta las dificultades de adaptarse a un nuevo país y sus efectos psicológicos, su condición de vida anterior y presente para compararla con la que puede tener al llegar a un nuevo país y aspectos sociales, morales, culturales y psicológicos tanto propios como de su familia. Por otra parte, la conciencia del individuo en el proceso de migración, toma en cuenta las costumbres de la sociedad sobre la migración, gastos y beneficios que podría obtener al migrar; por eso muchas personas que han tomado la decisión de irse al final deciden quedarse porque sienten que no les conviene o que les puede pasar algo en el camino si van; en cambio otras deciden irse y enfrentarse a los peligros con el fin de lograr su meta. Una vez que decide migrar y cuando llega al destino, la persona debe ver si logra adaptarse a ese país, si acepta su cultura, sus costumbres, si se siente cómodo con el resto de personas que son diferentes a 
él, ya que tienen una condición de vida diferente. Esto genera que haya personas que se regresen al país, porque no se sienten bien en ese país o porque simplemente extrañan a sus familias.

\section{Mercado laboral, migración y flujo de remesas}

\subsection{Introducción}

En el presente apartado se aborda el modelo de Harris-Todaro, el cual nos muestra que existe un flujo migratorio del área rural al área urbana en países subdesarrollados, debido a que pueden acceder a una renta esperada mayor dentro del sector formal y obtener la suficiente o completa cobertura de su fuerza de trabajo, así como la satisfacción de necesidades básicas, ya que la forma en que se logran cubrir dichas necesidades está en función del nivel de ingresos que recibe una persona por realizar un determinado trabajo. Pero, al verse un alto flujo de personas en el área urbana, llega un momento en que no todos pueden formar parte del sector formal de la economía; razón por la cual las personas pasan a formar parte del denominado sector informal, en el que se encuentran obligados a realizar diferentes actividades que les puedan ayudar a recibir un salario, caso en el cual El Salvador es un ejemplo claro. Pero en la mayor parte de los casos dicho sector no es capaz de ofrecer ingresos que logren cubrir el precio de la canasta de mercado, una razón muy fuerte que lleva a los salvadoreños a dejar el país y migrar hacia otros.
Existen diversas razones por las cuales las personas deciden migrar, una muy fuerte es que especialmente en las áreas rurales es poco el acceso que se tiene a servicios básicos, salud y educación, por lo que piensan que en las áreas urbanas es más fácil acceder y mejorar directamente estos aspectos.

\subsubsection{El modelo básico Harris-Todaro y la influencia sindical ${ }^{15}$}

Se parte de la idea que habrá un sector, el formal urbano, en el cual se pagan salarios más altos a comparación del sector informal urbano y del sector rural. Esto puede ocurrir por distintas razones entre las cuales se puede mencionar que en el sector formal urbano hay una mejor organización laboral que permite que existan sindicatos que puedan intervenir en el establecimiento de los salarios, además se puede caracterizar por ser un sector en donde se ofrecen prestaciones de la ley ; el salario alto, además, puede establecerse porque se contrata mano de obra de mejor preparación o puede ser como un incentivo para que las personas se esfuercen mas; mientras que en los otros dos sectores la mayor parte del trabajo se realiza 
entre familias por lo que no pueden haber incentivos a que exista un salario más alto.

\subsubsection{Caso con salario fijo en el sector urbano}

Existe un problema en el modelo descrito anteriormente. Se estableció que los salarios del sector urbano formal son flexibles, cuando en realidad dichos salarios son fijos, tan altos que no se pueden igualar a los salarios de mercado $\mathbf{W}^{*}$ (intersección de las curvas de absorción), en el grafico 12 se establecerá un salario del sector urbano formal por encima de la intersección de las curvas de absorción $\bar{W}$ y donde a este nivel salarial los empresarios ya no contratarán más allá de $\overline{L_{F}}$, pero la inquietud que surge es que toda esa gente no empleada $L-\overline{L_{F}}$ tiene que ir a parar a algún lugar. Por esto podría suceder que todas las personas se queden en el sector agrícola $L-\overline{L_{F}}$ y eso hará que los salarios bajen a un nivel $\underline{W}$ en dicho sector, por lo que evaluando una situación final, resulta que existe pleno empleo en los dos sectores pero las diferencias salariales de $\bar{W}$ y $\underline{W}$ no puede generar una situación de equilibrio, porque las migraciones siempre persistirán aunque exista pleno empleo siempre buscaran trasladarse al sector urbano formal. También se puede ver cómo surge el sector informal representado en el grafico por la brecha que Ilamaremos U. El sector agrícola no puede absorber mano de obra más allá de $\overline{L_{A}}$, al salario $\bar{W}$, por lo que existe un lugar donde están los desempleados encubiertos en el sector urbano informal, que son personas que muchas veces apenas logran subsistir, es decir, viven en miseria, esto como resultado de que no tuvieron mucha suerte cuando apostaron en encontrar trabajo en el sector de elevados salarios que es el sector urbano formal. En la decisión de emigrar a la ciudad para obtener un empleo en el sector formal, se corre el riesgo de no ser absorbido por dicho sector y las opciones que le quedan es regresar a trabajar al campo o buscar un lugar en el sector urbano informal, que bien podría ser un tercer sector en la economía.

\section{Grafico 12. Modelo Harris-Todaro: salario fijo en el sector urbano}

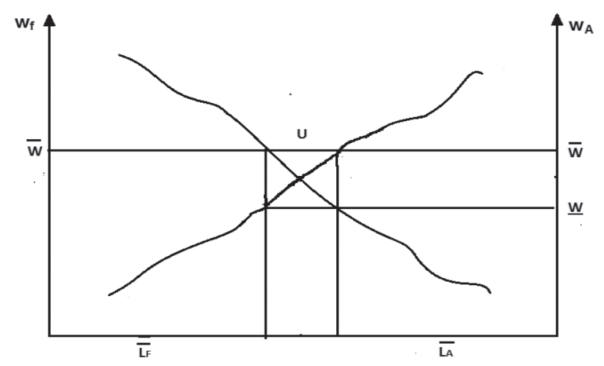

Fuente: Elaboración propia en base a Economía del Desarrollo. Debraj, R. Pág. 362 
Los emigrantes tienen dos opciones. La primera y segura es la de permanecer en el sector agrícola y la segunda es la de trasladarse al sector urbano, siempre en busca de salarios mayores. Los que no logran entrar a trabajar al sector formal, entran el sector urbano informal que es donde terminan todos aquellos que fracasaron en su intento por obtener un empleo en el sector formal, con un trabajo con bajos salarios.

Como se ha planteado una situación de probabilidades, el emigrante tiene que evaluar en base a expectativas, el salario esperado en el sector urbano y compararlo con el salario que gana en la agricultura. Se analizara un esquema donde se plantean las diferentes opciones para los emigrantes, a la derecha se tiene el sector agrícola, donde el salario se denotará como Wa, y al lado izquierdo se tiene al sector urbano formal cuyo salario es $\mathbf{W f}$ y la probabilidad de acceso a dicho sector se denotará como $\mathbf{P}$, que representa el cociente entre el numero de un empleo formal y la cantidad de puesto de trabajo formales que existen.

Para los que no tengan éxito en el sector formal está el sector urbano informal cuyo salario es
Wi, donde este salario es fijo, independientemente del número de trabajadores que existen en dicho sector y la probabilidad de acceso a dicho sector que es (1-p), entonces el salario esperado en el sector urbano, será la suma de las dos opciones que tienen es decir: $\mathbf{W f P + ( 1 - p ) W i}$ y este es el salario esperado que el trabajador que decida emigrar tendrá que comparar con el salario de la agricultura.

Sin embargo, hasta ahora solo se ha supuesto que las opciones de emigrar solo son al sector urbano formal e informal, pero existe la posibilidad de que el trabador quede desempleado lo que podemos llamarlo como un parado "visible", donde este obtiene un salario igual a cero. Entonces esto modifica el valor del salario esperado porque ahora necesitamos conocer la probabilidad de obtener un empleo en el sector informal, este tiene una probabilidad de acceso a dicho sector de $\mathbf{q}$, mientras sigue como un desempleado visible con la probabilidad $\mathbf{1 - q}$ entonces el valor esperado seria $\mathbf{q} \mathbf{W} \mathbf{i}+(\mathbf{1}-\mathbf{q}) \mathbf{0}=\mathbf{q} \mathbf{W} \mathbf{i}$, ahora el salario esperado total que tendría que evaluar el trabajador con respecto al salario percibido en la agricultura es $p W f+(1-p) q W i$. 


\section{Esquema 1. Opciones de un posible emigrante}

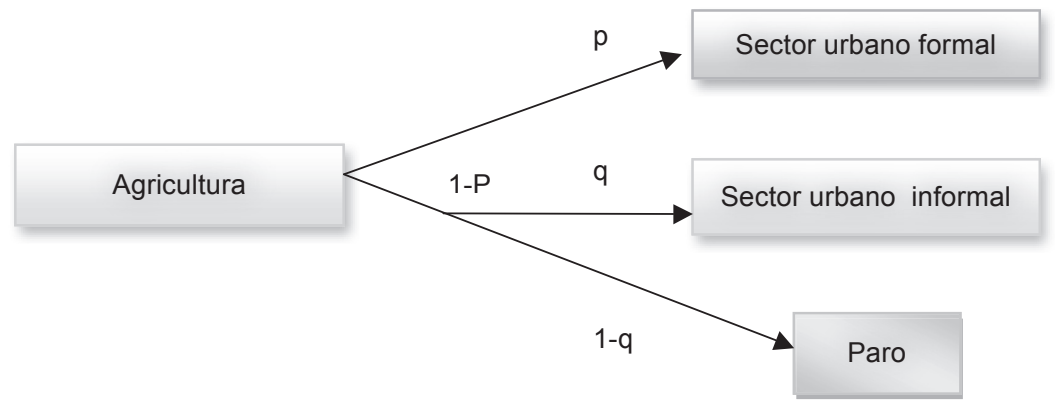

Después de realizar dicho análisis, los autores retomarán el caso más sencillo donde solo existen dos sectores urbanos: el formal y el informal, donde se establece que Li representa el empleo informal y $\mathbf{L f}$ representa en empleo formal. En ese caso, podemos ver el siguiente cociente:

\section{$L f / L f+L i$}

Donde:

Lf: Cantidad de puestos de trabajo.

Lf+Li: Indica la cantidad del total de personas que buscan un trabajo potencial.

El cociente entre esta dos expresiones nos dice la probabilidad que tiene un residente urbano de obtener un trabajo en el sector formal o informal.

A continuación se establecerá la condición de equilibrio planteada por Harris-Todaro, dado que la migración hacia el sector urbano es algo que se continuará dando. Entonces, se tendrá que considerar a la renta esperada de la migración y compararla con la renta verdaderamente percibida en la agricultura, y se llega a la siguiente expresión:

\section{$(\overline{\mathbf{L}} \mathbf{f} / \mathbf{L} \mathbf{f}+\mathrm{Li}) \mathbf{W f}+(\mathbf{L i} / \mathbf{L} \mathbf{f}+\mathrm{Li}) W i=W a$}

Esta es la condición de equilibrio de Harris-Todaro, en la cual ninguna persona esta incentivada a migrar de un sector a otro.

Los autores hacen una serie de observaciones que se expondrán a continuación:

1. Las personas que emigraron y encontraron trabajo estarán satisfechas de haberlo hecho, no así las que no corrieron la misma suerte.

2. La distribución del trabajo en los sectores de la economía determina la probabilidad de 
acceder a uno de ellos ya que por ejemplo si se sabe que el sector formal representa una pequeña proporción del empleo urbano entonces la gente que quiere emigrar a dicho sector lo evaluara un poco más porque no es muy seguro que encuentre trabajo.

3. La idea no es concebir que solo existen dos subsectores del sector urbano (formal e informal) o solo uno en la agricultura. El equilibrio se logra cuando lo salarios de los dos sectores serán iguales para alcanzar el nivel de migración de equilibrio, pero dichas expectativas pueden darse teniendo en cuenta más sectores en la economía, por ejemplo se puede tomar en cuenta un sector de desempleados donde los salarios son cero.

El modelo presentado anteriormente no siempre se comportara de esa manera, si no que dependerá del contexto donde se encuentra, por ejemplo, en un país donde la actividad económica se encuentra bajo un fuerte control empresarial, y donde los gobiernos pareciera que favorecen a estos grupos con las políticas económicas y donde exista poca fuerza sindical, entonces el comportamiento de los salarios será diferente, es decir, no necesariamente siempre el sector urbano tendrá salarios más elevados, es posible que paguen salarios miserables, pero tampoco se niega el hecho de que la fuerza de trabajo busca los mayores salarios, eso es algo que no lo negaremos, por la lógica de buscar cubrir las necesidades.

\subsubsection{Critica al modelo básico de Harris-Todaro $^{16}$}

El punto de partida en este modelo será que existe un fuerte control empresarial que se caracteriza por hechos como: "evidencia de colusión entre grupos empresariales, caída o estancamiento secular de los salarios reales por largo periodo además de una debilidad en la organización laboral o sindical". (Montesino, 2011. Duke y Godoy, 2006)

Se parte de un salario en el sector urbano formal por debajo del equilibrio debido al control empresarial en el mercado laboral pero donde los salarios del sector rural serán relativamente más bajos. Esto es así debido a que los salarios se han fijado por los empresarios, y produce la migración del sector rural al urbano.

Por tanto, a diferencia del modelo básico se incorpora el efecto del monopsonio en el sector urbano, gráficamente se ha agregado la curva del gasto marginal o el efecto monopsonio en el sector urbano que está por encima de la curva de oferta de trabajo, en 
la base del mismo se observará la mano de obra dirigida al sector formal urbano, informal o rural agrícola. Como, claro está, las personas emigrarán del campo a la ciudad, pero es muy probable que no todas obtengan empleo en el sector formal urbano, la expectativa que se hace de pasar a ser parte del sector informal provoca que los salarios del sector agrícola suban y baje el salario esperado en la ciudad. Para Harris-Todaro, esta migración se detendrá, cuando el salario esperado sea igual al salario agrícola, situación que se denomina la condición de equilibrio: ${ }^{5}$

$$
\left(\frac{L_{F}}{L_{F}+L_{I}}\right) W_{F}+\left(\frac{L_{I}}{L_{F}+L_{I}}\right) W_{I}=W_{A}
$$

Gráficamente el nivel de ocupación se establecerá en coherencia con el punto de intersección entre la curva de gasto marginal y la de absorción para el sector urbano. Además, se ubicará un salario para el empleo agrícola a un nivel más bajo con su respectiva curva de absorción y nivel de ocupación. Esta situación de que en ambos sectores haya bajos niveles de salario, aunque en uno más que en otro genera una disminución en el incentivo migratorio, mas no lo detiene. Por tanto, se observa un movimiento final de la curva de gasto marginal (GM1) a consecuencia de que la curva de oferta de trabajo en el sector formal también se ha desplazado, lo que eleva el empleo en el sector informal mientras que disminuye la mano de obra en el sector de la agricultura.

\section{Gráfico 13}

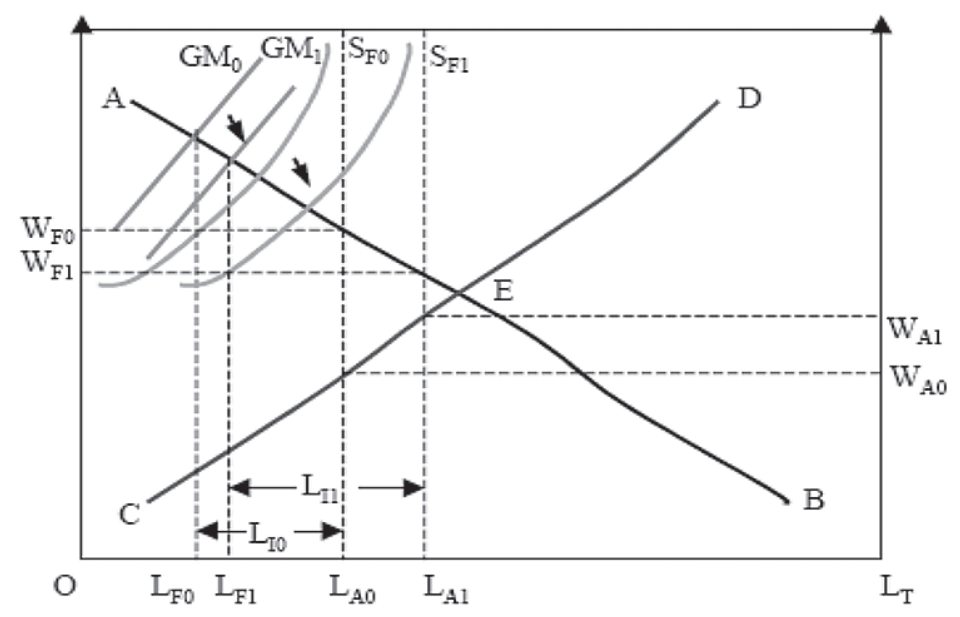

Fuente: Economía y desarrollo, Montesinos (2011) 
Se puede observar entonces que la emigración se debe a las diferencias salariales existentes. En primer lugar, por que los salarios son establecidos por los empresarios en el sector formal, mientras que en el sector informal predomina el empleo por cuenta propia, en el que las personas establecen su propia salario. El sector formal posee unos salarios inferiores a los de equilibrio y el sector agrícola no mejora en gran medida en términos salariales y esta situación persistirá mientras los salarios esperados en el sector urbano sean mayores que en el sector agrícola, además es posible observar la influencia que ejerce el monopsonio en el nivel de ocupación de las personas. A todo esto se le puede abonar el afán de las personas de tener unas condiciones de vida y trabajo humanas dignas que los llevan a buscar alternativas ante los problemas del desempleo, bajos salarios y otros problemas que aquejan a la sociedad. (Montesino, 2011).

\subsubsection{El modelo de Harris-Todaro coherente con la realidad de El Salvador y en el contexto de la teoría del valor de la fuerza de trabajo}

En la situación salvadoreña no existe una realidad muy aislada a la planteada previamente en la crítica, pues el sector informal constituye un tipo de desempleo encubierto, en el que puede haber personas desempleadas, tanto involuntaria como voluntariamente, que realizan iniciativas por su cuenta, es decir fuera del sector formal de la economía. Esta situación se presenta cuando las necesidades de las personas no son satisfechas, es decir, cuando las personas de forma independiente deciden dedicarse a la venta de bienes básicos, comida, ropa, accesorios etc. sin gozar de ningún tipo de prestaciones laborales.

La desventaja de las personas que laboran en este sector son varias, se puede mencionar: que no perciben una entrada o ingresos fijos, por ejemplo que si la persona se enferma no tiene acceso rápido al servicio de salud público o privado, además disminuye su capacidad de consumo; no gozan de vacaciones anuales pagadas, por lo que si decide descansar no percibe ingresos ese día y mucho menos hay una jornada fija diaria. Y está claro de acuerdo al modelo de Harris-Todaro que las personas que optan laborar en el sector informal son las que no logran conseguir empleo en el sector formal o porque pueden obtener los mismos ingresos monetarios que en el sector formal y debido a que no existen las mismas dificultades para insertarse es que se ven impulsados a realizar trabajos por su cuenta. En El Salvador está clara la incapacidad del sector formal de cubrir toda la mano de obra disponible en el mercado pues para el año 2012, únicamente 11,977 
personas hacen la diferencia para que estos dos sectores se igualen, es decir, que mas de la mitad de la población no logra posicionarse en el sector formal de la economía y tal como se observa en el gráfico a continuación, esta tendencia ha sido constante desde 2005.

\section{Grafico 14.0cupados por rama de actividad economica El Salvador 2005-2012}

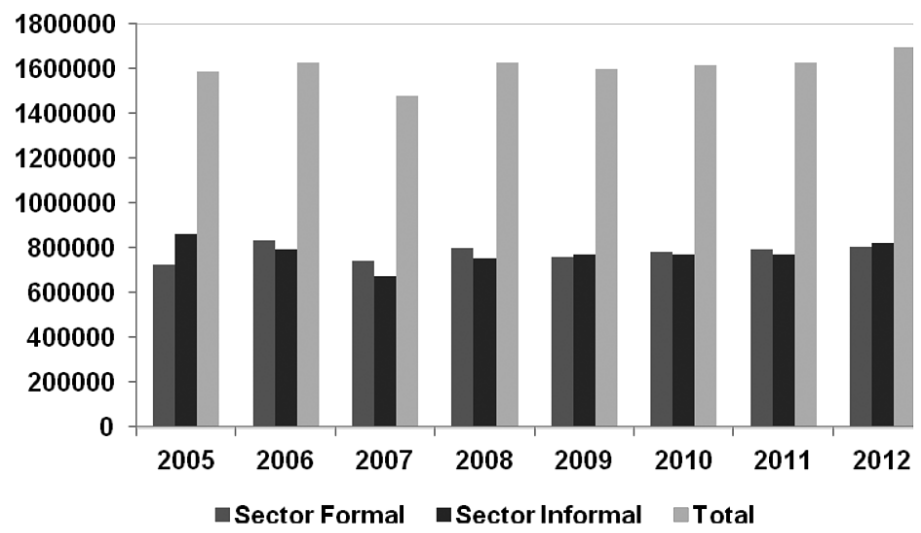

Por otra parte, si se toma en cuenta uno de los supuestos previamente establecidos que corresponde al de una débil organización de los trabajadores, específicamente en El Salvador, se hará referencia a la siguiente cita: "la tasa de sindicalización en El Salvador ha sido históricamente reducida. En el área rural se explica por la conducta anti-sindical de los tradicionales propietarios de plantaciones agrícolas y la legislación nacional que restringe la organización de los trabajadores agrícolas. En consecuencia este sector laboral (rural) tiene una tasa de organización de prácticamente cero" ${ }^{17}$
Una de las razones por las cuales no se logra el cumplimiento de los objetivos por parte de los sindicatos en El Salvador es que las federaciones están compuestas por sindicatos de diferentes actividades o rubros de la economía lo cual no permite una mejor organización ni focalización al momento de resolver problemas, además de que las ramas de la actividad económica con el mayor número de sindicatos no concentran la mayor cantidad de personas afiliados, situación que debería ser contraria, por ejemplo, el sector de la Industria Manufacturera cuenta con 66 sindicatos legalizados y solo registra al $23.17 \%$ del total de trabajadores afiliados a nivel nacional. 


\section{Grafico 15. Sindicatos por Rama de Actividad en El}

Salvador, Vigentes a Diciembre de 2010

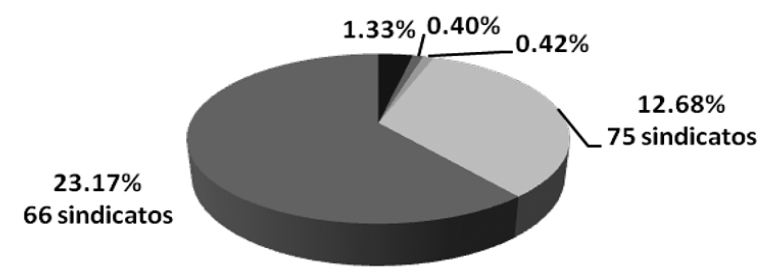

\section{- Agricultura $\square$ Pesca $\square$ Minas y Canteras $\square$ Comercio $\square$ Industria Manufacturera}

Fuente: Elaboración propia con base a MTPS, 2010

Retomando el modelo de Harris-Todaro, efectivamente el salario que se paga en el sector rural es y ha sido el menor pues para el año 2013 el sector agropecuario es remunerado con $\$ 115.50$ mientras que el sector industria tiene un salario de $\$ 241.23$, es decir, que se está hablando del doble de salario que perciben en este sector. Esta es una de las razones por la que ocurre un flujo migratorio del campo hacia la ciudad, pues con un salario de \$115.50 las personas tendrían una insuficiente cobertura del valor de su fuerza y ya no se diga con un salario mínimo de $\$ 97.20$ que fue el establecido para el año 2009. Primero hay que tener clara la desigualdad del ingreso pues a pesar de los aumentos que ha experimentado el salario mínimo no permite cubrir ni la canasta básica, lo cual afecta directamente las condiciones de existencia del trabajador.

Si no hay una plena cobertura del valor de la fuerza de trabajo se pueden presentar algunas de las siguientes situaciones:

1- "Deterioro de las condiciones nutricionales del trabajador

2- Deterioro psicosocial que entorpece la disposición a trabajar del obrero y su capacidad de captación y asimilación de tecnologías

3- Migración, esto equivale a la pérdida del más valioso recurso: el ser humano, las potencialidades de la economía se ven en este caso tremendamente reducidas" (Montesino, 2011).

La migración, alternativa a la que se opta como una salida viable al problema de los bajos salarios en el sector rural, se puede atribuir 
precisamente a que con estos salarios a las personas no se les posibilita vivir de manera digna lo que trae consigo problemas como la falta de acceso a servicios básicos como agua y luz. En El Salvador este problema representa un fuerte impacto para la población rural, pues únicamente un $69.8 \%$ posee acceso al agua por cañería, es decir, que el resto la obtiene de pozos y si se habla del servicio sanitario las personas que no disponen de este, corresponden al 9.2\% si se compara dicha situación con el área urbana en esta únicamente un $0.6 \%$ no poseen servicio sanitario, mientras que un $93.5 \%$ si posee acceso al agua y esta situación es relevante tomarla en cuenta pues esto aparte de no posibilitar una vida digna trae consigo enfermedades pues las personas viven en condiciones insalubres que ponen en riesgo la sobrevivencia de la principal fuerza generadora de valor.

Cabe entonces mencionar que entre las condiciones por las cuales las personas toman la decisión de migrar están las condiciones de pobreza, el desempleo y oportunidades limitadas. ${ }^{18}$

\section{Grafico 16.Proporcion de Hogares en pobreza} El Salvador 2012

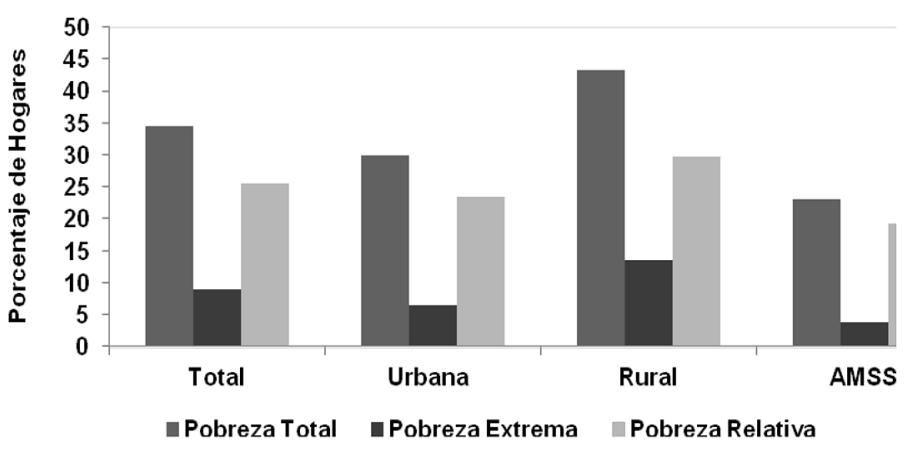

Fuente: Elaboración propia con base a DIGESTYC, 2012.

Una de las razones que es necesario sostener de nuestra economía, son las persistentes diferencias salariales entre el sector agrícola y el sector urbano que conlleva a que las personas busquen como alternativa la migración y a veces no solo a nivel del país, pues las ciudades son vistas como el "centro de progreso"19, sino hacia economías desarrolladas. A continuación se observara la tendencia de estancamiento que han tenido los salarios mínimos: 
Cuadro 6. Salarios mínimos por sectores 2005-2013

\begin{tabular}{|l|r|r|r|r|r|r|r|r|r|}
\hline \multicolumn{1}{|c|}{ Sector } & \multicolumn{1}{c|}{2005} & \multicolumn{1}{c|}{2006} & \multicolumn{1}{c|}{2007} & \multicolumn{1}{c|}{2008} & \multicolumn{1}{c|}{2009} & 2011 & Aumento (8\%) & \multicolumn{1}{c|}{2013} & Aumento (10\%) \\
\hline $\begin{array}{l}\text { Trabajadores } \\
\text { Agropecuarios }\end{array}$ & $\$ 74.10$ & $\$ 81.60$ & $\$ 85.80$ & $\$ 97.20$ & $\$ 97.20$ & $\$ 105.00$ & $\$ 7.80$ & $\$ 115.50$ & $\$ 15.50$ \\
\hline Comercio y Servicio & $\$ 158.40$ & $\$ 174.30$ & $\$ 183.00$ & $\$ 207.60$ & $\$ 207.60$ & $\$ 224.10$ & $\$ 16.50$ & $\$ 246.51$ & $\$ 22.41$ \\
\hline $\begin{array}{l}\text { Maquila Textily } \\
\text { Confeccion }\end{array}$ & $\$ 151.20$ & $\$ 157.20$ & $\$ 162.00$ & $\$ 173.10$ & $\$ 173.10$ & $\$ 187.50$ & $\$ 14.40$ & $\$ 206.25$ & $\$ 18.75$ \\
\hline Industria & $\$ 154.80$ & $\$ 170.40$ & $\$ 179.10$ & $\$ 203.10$ & $\$ 203.10$ & $\$ 219.30$ & $\$ 16.20$ & $\$ 241.23$ & $\$ 21.93$ \\
\hline
\end{tabular}

Ministerio de Trabajo y Previsión Social. "Salario Mínimo en El Salvador 2009-2013". Disponible en línea

\section{Grafico 17. Salarios minimos mensuales en El Salvador 2005-2013}

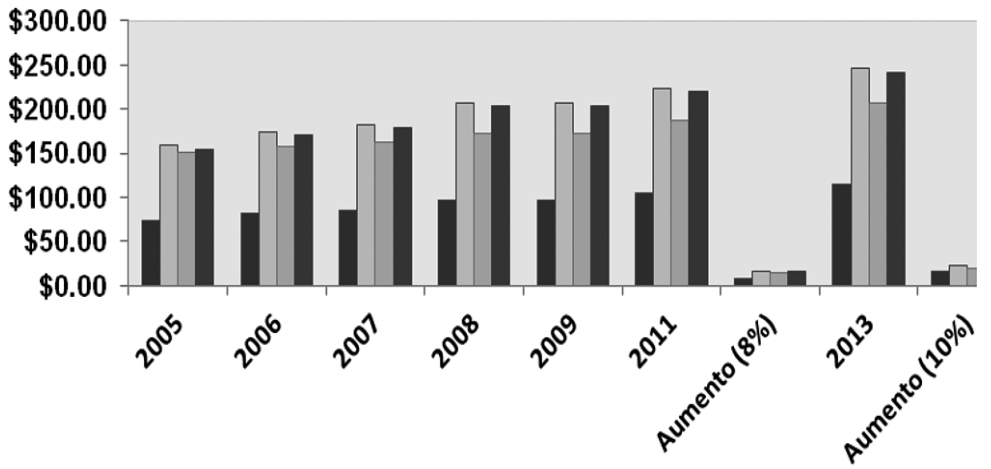

Ministerio de Trabajo y Previsión Social. "Salario Mínimo en El Salvador 2009-2013". Disponible en línea

Como se afirmaba anteriormente, el salario en el sector rural salvadoreño no le permite al trabajador cubrir sus necesidades básicas alimentarias ${ }^{20}$ lo cual atenta contra su reproducción, si se observa a continuación el costo promedio de la canasta básica alimentaria rural para 2013 es de $\$ 126.34$ mientras que anteriormente se menciono que el salario mínimo para el sector agropecuario es de $\$ 115.50$. Está claro entonces que este salario es incapaz de cubrir las necesidades básicas alimenticias de la población. Es decir, al trabajador salvadoreño se le paga por debajo del valor de su fuerza de trabajo, lo cual obviamente tiene un efecto negativo en su calidad laboral (Montesino, 1998). 


\begin{tabular}{|c|c|}
\hline \multicolumn{2}{|c|}{$\begin{array}{l}\text { Cuadro } 7 \text {. Indice de } \\
\text { Canasta basica alim } \\
\text { Rural (2005-2013) }\end{array}$} \\
\hline Año & Promedio Anual \\
\hline 2005 & $\$ 101.03$ \\
\hline 2006 & $\$ 99.18$ \\
\hline 2007 & $\$ 110.78$ \\
\hline 2008 & $\$ 127.87$ \\
\hline 2009 & $\$ 120.91$ \\
\hline 2010 & $\$ 118.43$ \\
\hline 2011 & $\$ 144.36$ \\
\hline 2012 & $\$ 133.29$ \\
\hline 2013 & $\$ 126.34$ \\
\hline
\end{tabular}

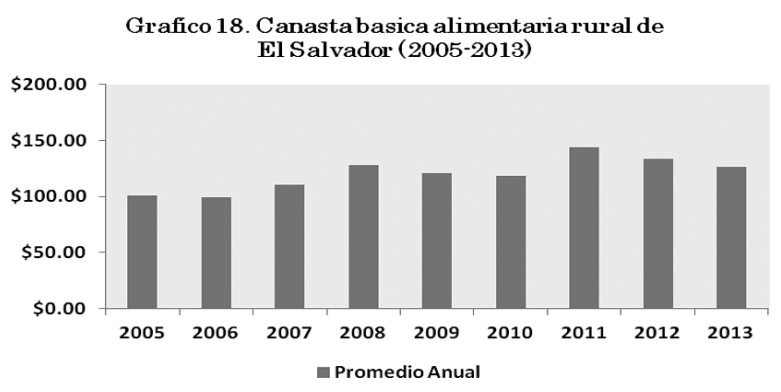

Fuente: Elaboración propia sobre la base de datos de DIGESTYC, 2013

Existiendo esta diferencia salarial entre ambos sectores, las personas se ven obligadas a migrar por la búsqueda de mejores salarios. Pero otra alternativa que las personas utilizan para resolver esta situación es la migración hacia países como EEUU principalmente, pues con lo que sus familiares reciben de remesas logran tener mayor capacidad adquisitiva. Aunque cabria destacar que mediante esto no se no se resuelve el problema de la incapacidad de los salarios mínimos para cubrir necesidades. Solo es una solución parcial, aunque es importante.

\section{Cuadro 8. Indice de precios al consumidor (IPC)}

\section{Canasta basica alimentaria}

Urbana (2005-2013)

\begin{tabular}{|l|r|}
\hline Año & Promedio Anual \\
\hline 2005 & $\$ 135.48$ \\
\hline 2006 & $\$ 138.15$ \\
\hline 2007 & $\$ 146.48$ \\
\hline 2008 & $\$ 171.19$ \\
\hline 2009 & $\$ 167.99$ \\
\hline 2010 & $\$ 168.29$ \\
\hline 2011 & $\$ 183.01$ \\
\hline 2012 & $\$ 174.60$ \\
\hline 2013 & $\$ 174.20$ \\
\hline
\end{tabular}

Grafico 19. Canasta basica alimentaria urbana de El Salvador (2005-2013)

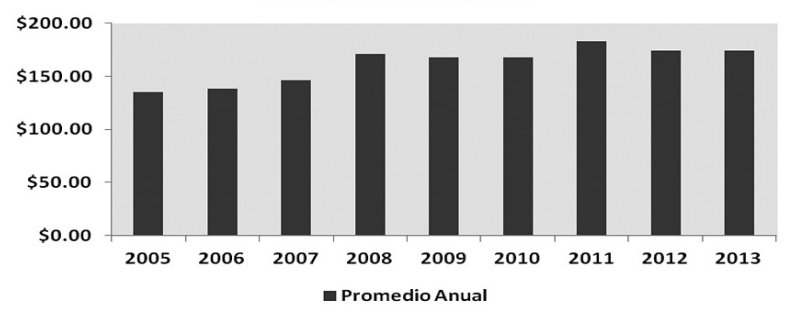

Fuente: Elaboración propia sobre la base de datos de DIGESTYC, 2013 
La incapacidad que tienen los salarios mínimos, previamente mencionados, para asegurar el acceso a servicios y necesidades fundamentales como la alimentación para reproducir la fuerza de trabajo, se reflejan cuando se comparan salarios con relación al costo de la CBA en estos últimos ocho años. A pesar de que ha habido aumentos en los salarios mínimos de la industria, comercio y servicios así como el sector agropecuario, siendo el último del $8 \%$ en 2011, se observa que esta se logra cubrir únicamente con los salarios percibidos para los sectores de la industria, comercio y servicio mientras que no para el sector rural. Es por eso que las personas no absorbidas por el sector formal o con muy bajos salarios en este sector, buscan también como solución el empleo en el sector informal urbano, pues probablemente les permita cubrir sus necesidades básicas aunque queden desprotegidos de beneficiarse de otras prestaciones de la ley.

Desde 2005 ha existido una tendencia de la población urbana a crecer mientras que la del sector rural ha disminuido como se observa a continuación:

\section{Grafico 20. Población por áreas de El Salvador 2005-2012}

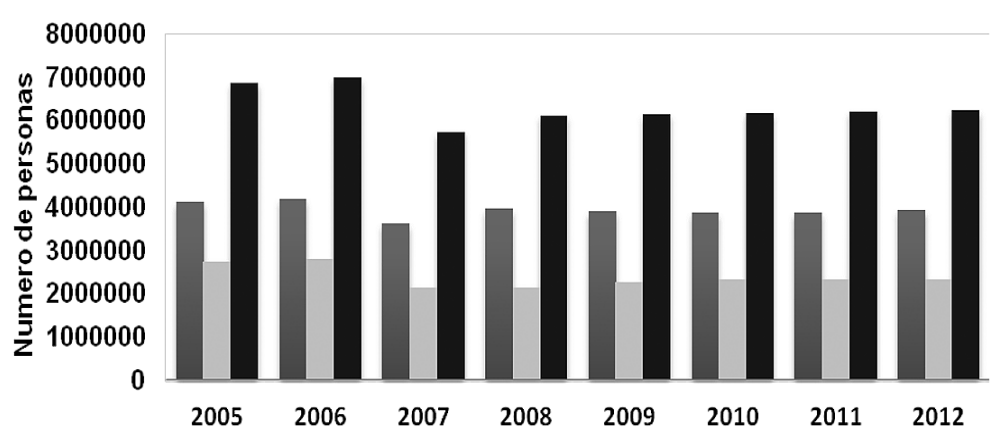

Fuente: Elaboración propia en base a datos obtenidos de la EHPM, 2005-2012.

Es considerable destacar cómo, al contrario del período 1961-1970, el área urbana estaba formada por $38.5 \%$ de la población, mientras que el área rural por el $61.5 \%$ restante. Para 2012 esta situación ha cambiado drásticamente, pues el mayor número de personas se concentra en el área urbana de nuestro país $(62 \%)$, mientras que solo el 38\% reside en el área rural del total de la población. Se observa, entonces, cómo el proceso migratorio ha cambiado estos porcentajes 
más en el mediano y largo plazo que en el período corto. Al año 2012 se tiene una población total de $6,249,262^{21}$ personas, de las cuales $2,338,850$ habitan en zonas rurales y $3,910,412$ en zonas urbanas en los diferentes departamentos de El Salvador; en comparación con el año 2005, en el cual se observa un total de 6,864,080. Se observa que en el periodo 2005-2012 hay una disminución en el área rural en comparación del área urbana, esto puede significar que las personas buscan mejores posibilidades de empleo, vivienda, acceso a educación y salud. Lo hacen en búsqueda de nuevas oportunidades que les permitan obtener una renta mayor que logre cubrir el valor de su fuerza de trabajo. Es notable además una disminución en la tasa de crecimiento de la población total de 2012 con respecto a 2005 del $-8.95 \% 22$ probablemente debido a la migración existente hacia otros países, como lo vimos anteriormente en el apartado 3 sobre la migración externa. Está claro entonces que con los niveles actuales de salarios mínimos en El Salvador la fuerza de trabajo no podría reproducirse y muchos menos si únicamente un miembro de la familia labora.

El grafico a continuación representa el ingreso promedio anual recibido por los distintos grupos étnicos (negros, blancos, hispanos, etc.) en los Estados Unidos, donde se observa que los ingresos que incluye a todas las razas son de $\$ 50,054$ y el de los hispanos es de $\$ 38,624$ manteniendo bastante estabilidad en el tiempo.

\section{Grafico 21. Ingreso Promedio real de los hogares por raza y origen hispano:}

1967-2011

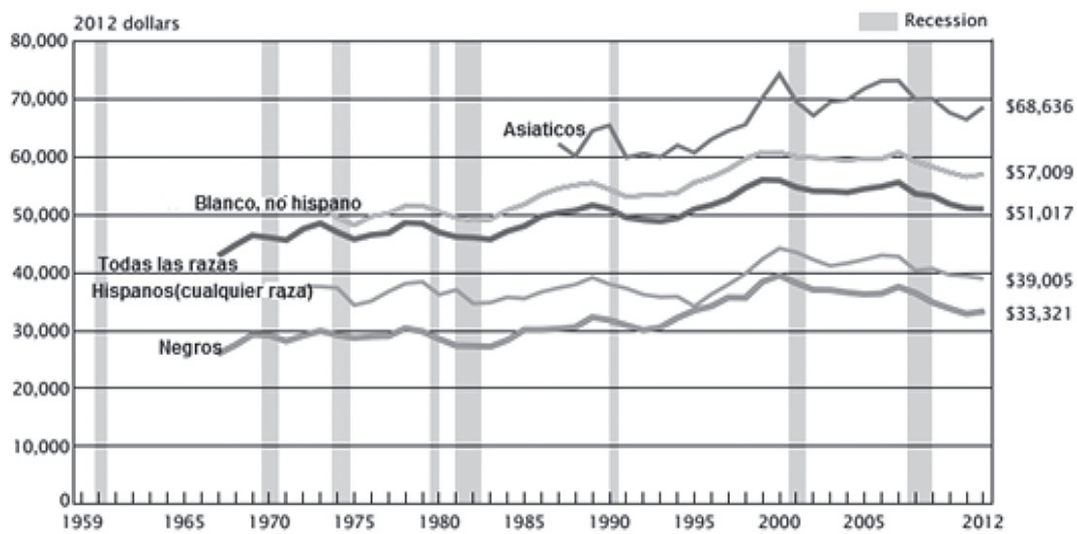

Fuente: Elaborado por la Oficina de Censos de Estados Unidos, Encuesta de población actual. 
Es un hecho que la realidad de nuestro país sigue lo establecido por el modelo Harris-Todaro, en el que se afirma que las migraciones se dan a raíz de la diferencia de los salarios en los sectores de la economía; solo que los flujos migratorios en el caso de El salvador se dan principalmente a nivel internacional, ya que las personas prefieren emigrar hacia los Estados Unidos. Las migraciones representan una fuga de la principal fuerza productiva que es la mano de obra, la cual está muy vinculada a la eficiencia en el proceso productivo y esto a su vez se relaciona con el valor de la fuerza de trabajo; dicho valor debe ser cubierto con el establecimiento de unos salarios que permitan recuperar el desgaste que los trabajadores tienen cuando producen, es decir, cubrir las necesidades físicas de los trabajadores que significa recuperar ese desgaste.

En el mercado laboral debe haber una incidencia y participación equilibrada de los sindicatos, ya que estos tienen como función velar por que se cumplan los derechos del trabajador a tener un salario digno, prestaciones sociales que recompensen en cierta medida su esfuerzo, etc. Está demostrado que el bloque empresarial no da espacio para que los sindicatos lleven a cabo su función en pro de la fuerza de trabajo para que esta se desarrolle plenamente y se convierta en el motor de la economía salvadoreña.

\section{Conclusiones}

- Una de las principales causas de la migración de la fuerza de trabajo salvadoreña es la insuficiente cobertura del valor de la fuerza de trabajo debido a los bajos salarios establecidos en el mercado laboral por el bloque empresarial dominante salvadoreño, el cual genera un deterioro de la principal fuerza productiva del país.

- El equilibrio del modelo de Harris-Todaro no se cumple en el mercado laboral salvadoreño, debido a que este funciona como un monopsonio, donde el valor esperado del salario en el sector urbano es demasiado bajo por lo que los flujos migratorios del campo a la ciudad y del país hacia EEUU no se detienen.

- La economía nacional se ha beneficiado de las remesas, lo que permite una relativa estabilidad económica porque ayuda a financiar el déficit comercial y la balanza de pagos. Además, las remesas impulsan la demanda en los sectores productivos, especialmente del sector terciario. Pero, a pesar de dicha situación, el mercado laboral salvadoreño 
no presenta mejoras, pues la minoría que decide cómo asignar los recursos o medios de producción, no los invierten o utilizan en actividades que generen mayor empleo y mejores condiciones de vida no lo impulsan por el afán ganancia que poseen.

- El flujo migratorio salvadoreño, especialmente hacia EE.UU., ha ido en aumento con el paso de los años. A través del análisis teórico y empírico acerca de los inmigrantes salvadoreños en Estados Unidos, es notable observar los cambios en sus condiciones de vida y de trabajo tanto en su país de origen como de destino. Ha sido evidente la situación de los salvadoreños, pues al analizar su nivel de educación, alimentación e inserción laboral en El Salvador, claramente hay una insuficiente cobertura del valor de la fuerza de trabajo que no permite su reproducción en condiciones óptimas y que los obliga a tomar la decisión de migrar, pues de esa manera logran estabilizar la situación de sus familias mediante las remesas percibidas.

\section{Referencias bibliograficas}

os Castro, A. (2004) "El impacto de las remesas en la pobreza de ingresos de los hogares salvadoreños". Disponible en línea http://www.uca.edu. sv/revistarealidad/archivo/4ce1b9d6095f3elimpacto.pdf [Acceso el 20 de junio de 2013]

os CEPAL, comunicado "Ingresos de Inversión Extranjera Directa en América Latina y el Caribe por país receptor, 2000-2012".Disponible en línea: http://www.eclac.org/prensa/noticias/comunicados/7/49847/ tabla_ied2012_ES.pdf [Acceso el 15 de Junio 2013]

os DIGESTYC, Dirección General de Estadística y Censo; Encuesta de hogares y propósitos múltiples, San Salvador, 2010.

os DIGESTYC, Dirección General de Estadística y Censo; Encuesta de hogares y propósitos múltiples San Salvador, 2005-2012.

os Debraj R. (1998) "Economía del desarrollo". España, Editorial Antoni Bosch.

os Department of Economic and Social Affairs Population Division (2002), World Population Ageing: 1950-2050. United Nations Publications, Nueva York.

os Duke, G.; Godoy, L.; (2006) "La incidencia sobre el control empresarial sobre el mercado laboral y la agencia en El Salvador". Universidad Centroamericana José Simeón Cañas (UCA). San Salvador. 
os DIGESTYC, Dirección General de Estadística y Censo. "Estimaciones y proyecciones de población a nivel nacional y departamental", 2009. Disponible en línea: http://www.censos.gob.sv/util/datos/proyecciones. pdf

os Fondo Multilateral de Inversiones (2013) "Las Remesas a América Latina y el Caribe en 2012: comportamiento diferenciado entre subregiones". BID.

os Hernández, X. (2004) La gestión urbana desde el enfoque de desarrollo económico. Disponible en línea: http://www.uca.edu.sv/revistarealidad/ archivo/4cd42f686ff1dlagestionurbana.pdf [Acceso el 18 de Junio de 2013]

os Ministerio de Trabajo y Previsión Social, Informe Estadístico mensual, Abril,2013. Disponible en http://www.mtps.gob.sv/ [Acceso el 15 de Junio 2013]

os Montesino, M. (2000). "EL IMPACTO DE LOS PROGRAMAS DE AJUSTE ESTRUCTURAL Y ESTABILIZACION ECONOMICA EN EL SALVADOR". Disponible en línea: http://www.repo.funde.org/647/1/SAPRIN-SV.pdf [Acceso el 15 de Junio 2013]

os Ministerio de Trabajo y Previsión Social. "Salario Mínimo en El Salvador 2009-2013". Disponible en línea : http://www.mtps.gob.sv/index. php?option=com_content\&view=article\&id=1366:salario-minimo-en-elsalvador-2009-2013\&catid=25:avisos-ciudadano\&ltemid=76 [Acceso el 15 de Junio 2013]

os Marx, K. (2001), El Capital Libro I, vol. 2. Edición Siglo XXI.

os Montoya, A. (1998). Economía Crítica. Editores Críticos, San Salvador.

os Montesino, M. (2011). Economía y desarrollo: racionalidad reproductiva y valor de la fuerza de trabajo en la gestión del desarrollo. UCA Editores. San Salvador

os Montesino, M. (2006) "Enfoque teórico de la economía abierta de servicios y la economía de remesas del trabajo". Estudios Centroamericanos (ECA). Numero 695. Volumen 61. San Salvador

os Márquez, Cuellar y Guevara (2005) "Economía de remesas del trabajo: eficiencia de la racionalidad solidaria". Universidad Centroamericana José Simeón Cañas (UCA). San Salvador

os PNUD. Informe sobre el desarrollo humano 2011. "Sostenibilidad y Equidad: un mejor futuro para todos". 
os PNUD. Informe sobre el desarrollo humano 2005."Una mirada al nuevo nosotros: El impacto de las migraciones"

os PNUD. Informe sobre el desarrollo humano 2007-2008. "El empleo en uno de los pueblos más trabajadores del mundo".

os PNUD. Informe sobre Desarrollo Humano 2013."El ascenso del Sur :progreso humano en un mundo diverso"

os Pagés, C. (2010), "La era de la productividad: cómo transformar las economías desde sus cimientos". BID

os Plataforma Interamericana de derechos humanos (Capítulo El Salvador) (2009)" Informe alternativo relativo al cumplimiento por El Salvador de la Convención Internacional sobre la Protección de los Derechos de todos los Trabajadores Migratorios y sus familias" Disponible en línea: http://www2.ohchr.org/english/bodies/cmw/docs/ngos/MPDM_ElSalvador9.pdf [Acceso el día 20 de Junio de 2013]

os Revista Trimestral del Banco Central de Reserva de El Salvador, Disponible en línea: http://www.bcr.gob.sv/esp/ [Acceso el 18 de Junio 2013]

os Revista anual del PNUD de El Salvador, Disponible en línea: http://www. pnud.org.sv/2007/component/option,com_docman/task,doc_download/ gid,260/ltemid,56/

\section{Notas}

1 Informe sobre Desarrollo Humano 2013

2 Encuesta de Hogares y Propósitos Múltiples, EHPM 2012

3 Ministerio de Trabajo y Previsión Social

4 CEPAL, comunicado INGRESOS DE INVERSIÓN EXTRANJERA DIRECTA EN AMÉRICA LATINA Y EL CARIBE POR PAÍS RECEPTOR, 2000-2012

5 Organización para la Cooperación y el Desarrollo Económico

6 OCDE. Mejores políticas para una vida mejor. Disponible: http://www.oecd. org/centrodemexico/laocde/

7 PERCEPCIONES DE LA OCDE Capital humano; Brian Keeley

8 Ver cuadro anexo 3.1

9 Ver grafica 3 anexo

10 Fuerza de trabajo e ingreso promedio Fuente INFS Costa rica 1987-2009

11 Capitulo 2 "Migración, Remesas y Desarrollo Humano de los salvadoreños en Estados Unidos en El Salvador"

12 Mas detalle en: La dinámica de las migraciones, brain drain y brain gain: una perspectiva desde Centroamérica, Cabrera, Oscar(2011)

13 Informe alternativo relativo al cumplimiento por El Salvador de la Convención Internacional sobre la Protección de los Derechos de todos los Trabajadores Migratorios y sus familias,2009 
14 Revista trimestral del Banco Central de Reserva, ver en línea: http://www.bcr. gob.sv

15 Ray. D Economía del desarrollo. Antoni Bosch editor. España 1998.P.360

16 Montesino. Economía y desarrollo: racionalidad reproductiva y VFT en la gestión del desarrollo (2011) Pag.276

17 CENTRA: El Sindicalismo Actual (1993) Pág. 208

18 Enfoque teórico de la economía abierta de servicios y la economía de remesas del trabajo, ECA Montesino, M. (2006)

19 La gestión urbana desde el enfoque de desarrollo económico. Hernández, X. (2004)
20 Existe un relevante defecto en el uso de las canastas básicas nutricionales como indicadores del valor de la fuerza de trabajo, y es el hecho de que al ser el resultado de encuestas nada asegura que realmente reflejen los hábitos de consumo necesitados por los trabajadores sino aquellos a los que se han adaptado debido a los bajos salarios y a los mecanismos compulsivos del sistema capitalista (Montesino M. 2000)

21 Ver cuadro Anexo 4.9 para verificación de datos

22 Datos de EHPM 2005-2012 